\title{
The financial accelerator in an evolving credit network
}

\author{
Domenico Delli Gatti ${ }^{a}$, Mauro Gallegati ${ }^{\text {b }}$, Bruce Greenwald ${ }^{\mathrm{c}}$, Alberto Russo ${ }^{\mathrm{b}, *}$, \\ Joseph E. Stiglitz ${ }^{\mathrm{C}}$
}

a Institute of Quantitative Methods and Economic Theory, Catholic University of Milan, Largo Gemelli 1, 20123 Milan, Italy

b Department of Economics, Polytechnic University of Marche, Piazzale Martelli 8, 60121 Ancona, Italy

c Columbia University, Uris Hall, 3022 Broadway, New York, NY 10027, USA

\section{A R T I C L E I N F O}

Available online 23 June 2010

\section{JEL classification:}

E32

D85

C63

\section{Keywords:}

Business fluctuations

Financial instability

Bankruptcy chains

\begin{abstract}
A B S T R A C T
We model a credit network characterized by credit relationships connecting (i) downstream (D) and upstream (U) firms and (ii) firms and banks. The net worth of D firms is the driver of fluctuations. The production of D firms and of their suppliers ( $U$ firms) in fact, is constrained by the availability of internal finance-proxied by net worth - to the D firms. The structure of credit interlinkages changes over time due to an endogeneous process of partner selection, which leads to the polarization of the network. At the aggregate level, the distribution of growth rates exhibits negative skewness and excess kurtosis. When a shock hits the macroeconomy or a significant group of agents in the credit network a bankruptcy avalanche can follow if agents' leverage is critically high. In a nutshell we want to explore the properties of a network-based financial accelerator.
\end{abstract}

(c) 2010 Elsevier B.V. All rights reserved.

\section{Introduction}

How do financial factors affect business fluctuations? The standard answer to this question in contemporary macroeconomics goes under the heading of financial accelerator, which essentially tells the following story: "To buy new capital goods, firms rely on several sources of financing. These include internal funds, such as retained earnings or capital infusions from firm owners, and external funds, such as the proceeds from loans and the sales of stocks and bonds. The amount of internal funds is related to the firm's cash flow. In response to a slowdown in sales, cash flow will likely decline, reducing the amount of internal funds and therefore increasing the amount a firm needs to obtain from external finance. But lenders will be less willing to loan funds to firms with smaller cash flow, and the value of firms' collateral is also likely to have decreased, further reducing their ability to obtain loans. Hence firms might be forced to reduce their investment. This reduction in turn will lead to lower output, lower cash flow, and yet again lower investment leading to a further deceleration in output. This theory provides a possible explanation for why changes in the amount of investment can have a multiplier impact on the broader economy" (Economic Report of the President, 2005, p. 59).

Central to this story is information, not only about the conditions of the parties in a credit relationship but also about the incentives that they face. The lender has to assess the risk involved in extending credit to the borrower, i.e. her ability and willingness to fulfill debt obligations. But information is asymmetric so that such an assessment is at best incomplete. In this context, a simple and easily available indirect sign of the borrower' s creditworthiness is a measure of her financial soundness captured, for instance, by net worth.

\footnotetext{
* Corresponding author.

E-mail address: alberto.russo@univpm.it (A. Russo).
} 
The models of the financial accelerator available so far, in particular Bernanke and Gertler $(1989,1990)$ and Bernanke et al. (1999), are based on the representative agent assumption. In the market for funds, for instance, a representative borrower interacts with a representative lender. A change in the representative borrower's net worth, therefore, is a metaphor for a change in aggregate net worth. As a consequence the financial accelerator works its way through the macroeconomy by means of changes in a proxy of economy wide financial robustness-aggregate net worth or cash flow. In the models - and generally also in the real world - this aggregate variable is pro-cyclical: for instance, in a recession, the financial accelerator effect "is roughly proportional to the size of the decline in GDP, since the change in cash flow and the value of collateral would be expected to be roughly proportional to the decline in output." (Bernanke and Gertler, 1989 , 1990; Bernanke et al., 1999).

By definition, this aggregate view of the financial accelerator abstracts from the complex nexus of credit relationships among heterogeneous borrowers and lenders that characterize modern financially sophisticated economies. This shortcut simplifies the analysis to a great extent but is a serious drawback because the current literature ignores by construction at least three fundamental features of the real world amplification mechanism based on the effects of shocks on the network of credit relationships.

First and foremost, in the aggregate view, by construction the shock which originates the fluctuation is aggregate, i.e. uniform across agents. But in the real world an idiosyncratic shock can well be the source of an epidemic diffusion of financial distress which usually translates into a contraction of real GDP. In other words, in a financial network idiosyncratic shocks usually do not cancel out in the aggregate, especially if they hit crucial nodes (hubs) of the network.

Second, the aggregate view does not capture the fact that the spreading of a financial disease may proceed at different speeds in different parts of the macroeconomy. For some agents, financial robustness may be pro-cyclical-as predicted by the aggregate view-while for other agents it is financial fragility that may be pro-cyclical. In Minsky's financial instability hypothesis, for instance, the financial fragility of borrowers increases during "prosperous times" sowing the seeds of the next financial crisis and recession. When the economy is booming, in fact, firms in fact are eager to increase their debt (relative to net worth) and banks are willing to accommodate their financing needs because of the widespread expectations of abundant profits. More recently Adrian and Shin (2008) have brought attention to the pro-cyclicality of leverage, i.e. the typical measure of financial fragility, of some specialized lenders-especially investment banks. The unwinding of positions during the crisis in an attempt at de-leveraging has been an important factor of amplification of the crisis itself.

Last but not least, in a credit network the financial accelerator can lead to an avalanche of bankruptcies. Suppose, for instance, that a firm goes bust. Both the suppliers and the banks which made business with the bankrupt firm will bear the brunt of the default. The deterioration of the bank's financial condition due to the borrower's bankruptcy may be absorbed if the size of the loan is small and/or the bank's net worth is high. If this is not the case, also the bank goes bankrupt. If the bank survives, however, it will restrain credit supply and/or make credit conditions harsher-raising the interest rate on loans across the board-for all its borrowers. Therefore, the default of one agent can bring about an avalanche of bankruptcies. While the proximate cause of the bankruptcy of a certain firm in the middle of the avalanche is the interest rate hike, the remote cause is the bankruptcy of a firm at the beginning of the avalanche that forced the banks to push interest rates up. The interest rate hike leads to more bankruptcies and eventually to a bankruptcy chain: "the high rate of bankruptcy is a cause of the high interest rate as much as a consequence of it" (Stiglitz and Greenwald, 2003, p. 145). An avalanche of bankruptcies therefore is due to the positive feedback of the bankruptcy of a single agent on the net worth of the "neighbours", linked to the bankrupt agent by credit links of one sort or another.

Bankruptcy cascades may be of different size depending not only on the magnitude of the shock but also on the topology of the network. When the corporate and/or the banking sector are polarized, the vulnerability of the network to a shock-i.e. systemic risk-increases because the default of a highly connected agent, albeit a relatively rare event, may generate a non-negligible cascade of bankruptcies.

These are the crucial aspects of real world financial accelerator which we want to investigate. Therefore we must focus on the complex pattern of credit relationships, which is a natural research issue to be dealt with by means of network analysis. It is straightforward, in fact, to think of agents as nodes and of debt contracts as links in a credit network. In a nutshell we want to explore the properties of a network-based financial accelerator.

There are influential examples of network analysis applied to credit networks. ${ }^{1}$ Allen and Gale (2001), for instance, put forward a theory of "financial contagion" in a network model of the interbank market. In this case, however, the networks considered are very simple and easy to study because they consist of few nodes organized in canonical forms. A nonnegligible and growing literature has developed from these premises on the network of the interbank market (Freixas et al., 2000; Furfine, 2003; Boss et al., 2004; Iori et al., 2006; Nier et al., 2007). A different but no less important line of network research (Boissay, 2006; Battiston et al., 2007) focuses on the trade-credit relationships within the corporate sector, i.e. among suppliers of intermediate goods and producers of final goods along the "supply chain".

\footnotetext{
${ }^{1}$ Networks are the main subject of a rapidly growing literature which applies the conceptual and analytical tools already developed in sociology, computer science and physics to economics and/or provides new notions and methods to be applied specifically to economic phenomena. Recent books by Jackson (2008), Vega-Redondo (2007), and Goyal (2007) describe the frontier of research on economic networks.
} 
These strands of network literature analyze specific credit relationships: among banks on the interbank market or among firms along the supply chain. Building upon ideas expounded first in Stiglitz and Greenwald (2003, Chapter 7), we pursue a more general and "encompassing" line of research. We model a credit network consisting of households, firms and banks. Agents are linked by inside credit (i.e. credit relationships connecting firms belonging to different layers of the same industry - the corporate sector-or connecting banks on the interbank market) and outside credit (i.e. credit relationships connecting agents belonging to different sectors, i.e. banks and firms).

Previous and preliminary attempts at building a model of these interactions can be found in Delli Gatti et al. (2006, 2009). In the present paper we specify a mechanism for the selection of partners/lenders on the part of borrowers which governs the evolution of the network structure-essentially driven by financial factors-and compare the properties of this endogenously evolving network with those of a random matching mechanism in the working of a network-based financial accelerator. In general, we analyze the interplay between microeconomic shocks and macroeconomic dynamics, stressing the relevance of financial factor in amplifying the effects of a given distribution of idiosyncratic shocks. We also consider that economic downturns may affect agents' financial conditions in the credit network, possibly generating a vicious circle of financial deleveraging and economic depression. All in all, we propose an extension of the financial accelerator framework focussing on the transmission of financial distress (through the bankruptcy channel) among heterogeneous agents whose financial fragility (Minsky, 1982) may amplify business fluctuations, depending on the complex configuration of credit interlinkages.

Jackson (2005) distinguishes between a random graph approach to network formation, borrowed from physics, and the game theoretic approach specifically designed to deal with economic networks. The former is, in a sense, "mechanical": network formation is purely stochastic or the product of an ad hoc algorithm. The latter focuses on "equilibrium" networks, where links are formed as a consequence of cost-benefit analysis on the part of self-interested agents.

The approach followed in the present paper is half-way between the two: the partner choice rule allocates links to nodes as a consequence of the search for the lowest price (interest rate). In every period, an agent in search of a partner in a transaction-a customer in search of a supplier, a firm in search of a bank-has a certain probability of switching to a new partner depending on the difference between the minimum price (interest rate) in a randomly selected subset of agents and that set by the previous partner. The number of links connecting the nodes changes over time so that the topology of the network is also in a process of continuous evolution.

We study the properties of the model by means of simulations, which show that a business cycle at the macroeconomic level can develop as a consequence of the complex interaction of the agents' financial conditions. In other words, statistical regularities emerge as a self-organized process at the aggregate level. In particular, aggregate growth rates exhibit negative skewness and excess kurtosis, stressing the relevance of negative extreme events in such a complex network. A comparison with a random matching mechanism shows that the endogenous partner selection process leads to a right-skew degree distribution of the credit network which has some influence on systemic risk due to the diffusion of financial distress across sectors.

The paper is organized as follows. In Section 2 we sketch the main assumption concerning the economy under scrutiny. Sections 3 and 4 are devoted to the price/quantity decisions of agents, i.e. firms and banks, respectively. In Section 5 we explain the mechanism governing the choice of the partner. In Section 6 we analyze the main determinants of profits. Section 7 is devoted to the relationship between profits, net worth and bad debt. In Section 8 we discuss the simulation results. Section 9 concludes.

\section{The environment}

In this section we outline the general features of the credit network under scrutiny. Our economy is populated by households (final consumers and labour suppliers), firms and banks. The corporate sector consists of two layers of firms. Downstream (D) firms-indexed by $i=1,2, \ldots, I$-produce consumption goods, while upstream (U) firms-indexed by $j=1,2, \ldots J$-supply intermediate inputs to D firms. Banks, indexed by $z=1,2, \ldots, Z$, extend credit to firms in both layers. D firms are pure borrowers: they borrow from U firms (trade credit) and from banks (bank loans). Banks are pure lenders: they lend to D and U firms. U firms are borrowers and lenders at the same time: they borrow from banks and lend to D firms.

Adopting a financing hierarchy perspective, we assume that the scale of production of D firms is constrained only by their net worth. Since U output is determined by the input requirements of D firms, the net worth of D firms turns out to be the main driver of fluctuations. Changes in the net worth of D firms, in fact, bring about changes in the same direction of $U$ production. An unexpected shock to a D firm affects the credit relationship between the firm and its supplier, on the one hand, and between the firm and the bank on the other.

If the shock is large enough, the $\mathrm{D}$ firm may be unable to fulfill debt commitments and may go bankrupt. The bankruptcy of a borrower would be irrelevant if, so to speak, the agent were an "island". In a networked economy, however, bankruptcy will not be an isolated and therefore insignificant phenomenon. For instance, the bankruptcy of a D

\footnotetext{
${ }^{2}$ In order to keep the analysis simple, the number of firms and of banks is exogenous. Since in our framework agents can leave the market due to bankruptcy, in order to preserve constancy of the number of agents we have to apply a one-to-one replacement procedure when an agent goes bankrupt.
} 
firm may bring about the default of the U firm with which it interacts along the supply chain. Moreover "bad debt"-i.e. non-performing loans-affects the net worth of banks, which can also go bankrupt. If they manage to survive, they will react to the deterioration of borrowers' financial conditions increasing the interest rate. Hence borrowers may incur additional difficulties in servicing debt. It is indeed clear that a relatively small shock may be amplified by the network of credit relationship, an effect which we label the network-based financial accelerator.

Interdependence may assume different forms. For instance, the bankruptcy of a D firm may bring about the default of the U firm with which it interacts along the supply chain. Moreover "bad debt"-i.e. non-performing loans-affects the net worth of banks, which can also go bankrupt. If they manage to survive, they will react to the deterioration of borrowers' financial conditions increasing the interest rate.

The endogenous evolution of credit interlinkages affects the extent of bankruptcies' diffusion: the bankruptcy of a highly connected agent increases the probability of bankruptcy diffusion across the network.

All in all, we consider four markets: consumption goods, intermediate inputs, labour and credit. "Quantities", i.e. the amount of consumption and intermediate goods produced, labour employed and credit extended are not directly affected by "prices". They depend, instead, as we have already pointed out above, on the financial conditions of the agents involved.

Prices, however, play an essential role in (i) shaping the evolving topology of the network and (ii) determining the degree of agents' financial vulnerability.

As to (i), in two of the markets considered, i.e. the markets for intermediate inputs and for bank loans, the mechanism of partner selection implies that the price charged by a supplier to a customer-which incorporates the interest rate on commercial paper-and the interest rate on bank loans affects the number of clients of each $U$ firm and the number of loan applications to each bank, respectively, and therefore impacts upon the evolution of network connectivity.

As to (ii), prices are important determinants of profits, which in turn affect the accumulation of net worth and financial fragility. The financial vulnerability of an agent therefore is affected by the dynamics of prices.

On the markets for consumption goods and on the labour market, "prices" are exogenously determined and play a less relevant role. Following Greenwald and Stiglitz (1993), we assume that on the market for consumption goods, prices are governed by a random process. As to the labour market, we appeal to real rigidity of one sort or another so that we feel entitled to take the real wage as given and constant. In these cases, for the sake of simplicity and clarity we have admittedly adopted a very crude "theory" of prices. We will relax these assumptions and enrich the theory in further extensions of the present model. Our conjecture, however, is that qualitatively the main results of the model-in particular the output of simulations-will not be remarkably affected by this relaxation.

There are two goods, a consumption good and an intermediate good. D firms produce a perishable consumption good using labour and intermediate goods. For simplicity and as a first approximation to a more realistic setting, we assume that firms sell all the output they produce at a stochastic price.

U firms produce the intermediate good "on demand" with a technology that requires only labour. Therefore U firms do not hold inventories of intermediate goods. We are ruling out by construction the possibility of avalanches of output due to the mismatch of demand and supply of intermediate goods along a supply chain à la Bak et al. (1993).

The financial side of the economy is characterized by two lending relationships: (i) downstream and upstream firms obtain credit from banks; (ii) downstream firms buy intermediate goods from upstream firms by means of a commercial credit contract.

The structure of the network of expenditure, production and credit relationships evolves endogenously due to a decentralized mechanism of interaction: in every period each D firm looks for the $U$ firm with the lowest price of intermediate goods; at the same time each firm searches for the bank with the lowest interest rate.

\section{Firms}

The core assumption of the model is that the scale of activity of the $i$ th $\mathrm{D}$ firm at time $t$-i.e. the level of production $Y_{i t}$-is an increasing concave function of its financial robustness, captured by net worth $A_{i t}$ :

$$
Y_{i t}=\phi A_{i t}^{\beta}
$$

where $\phi>1,0<\beta<1$ are parameters, uniform across D firms. The equation above represents the financially constrained output function.

One can think of Eq. (1) as the solution of an optimization problem on the part of the firm. According to Greenwald and Stiglitz (1993) for instance the problem of the firm consists in maximizing expected profits $E\left(\pi_{i}\right)$ net of bankruptcy costs $C_{i}$ weighted by the probability of bankruptcy $\Omega_{i}$. From the definition of profits follows that they are an increasing function of output $Y_{i}$ given net worth $A_{i}: \pi_{i}=\pi\left(Y_{i} ; A_{i}\right)$. Bankruptcy costs are assumed to be increasing with the firm's size: $C_{i}=C\left(Y_{i}\right)$. Finally, from the definition of the probability of bankruptcy, it turns out that it is increasing with the scale of activity, given net worth: $\Omega_{i}=\Omega\left(Y_{i} ; A_{i}\right)$. An increase of financial fragility, in fact, captured by a reduction of net worth, brings about an increase of the probability of bankruptcy. In the end the Greenwald-Stiglitz characterization of the problem of the firm is:

$$
\max _{Y_{i}} V\left(Y_{i} ; A_{i}\right)=E\left(\pi\left(Y_{i} ; A_{i}\right)\right)-C\left(Y_{i}\right) \Omega\left(Y_{i} ; A_{i}\right)
$$


whose solution is

$$
Y_{i}=\operatorname{argmax} V\left(Y_{i} ; A_{i}\right)=f\left(A_{i}\right)
$$

with $f^{\prime}>0$. Eq. (1) can be considered an element in the set of functional forms consistent with (2).

The concavity of the financially constrained output function (1) captures the idea that there are "decreasing returns" to financial robustness: the increase in output associated to a given increase of net worth is lower if the firm is already financially robust. Let us denote with $f_{x}(x)$ the derivative of the generic function $f(x)$ w.r.t. $x$. The FOC of the firm's problem can be represented by $V_{Y}\left(Y_{i} ; A_{i}\right)=0$ so that

$$
f^{\prime}=-\frac{V_{Y A}\left(Y_{i} ; A_{i}\right)}{V_{Y Y}\left(Y_{i} ; A_{i}\right)}
$$

Therefore, the slope of the financially constrained output function is positive-i.e. $f^{\prime}>0$ - if the signs of the numerator and of the denominator are different. The assumption implicitly made in the Greenwald-Stiglitz framework is that the numerator is negative and the denominator is positive. In order to derive the sign of the first order derivative of the financially constrained output function, therefore, one has to sign the second order derivatives of the objective function w.r.t. its arguments, output and net worth. The returns to financial robustness are captured by the second derivative of the financially constrained output function, i.e. by the sign of the following expression:

$$
f^{\prime \prime}=-\frac{\partial}{\partial A_{i}} \frac{V_{Y A}\left(Y_{i} ; A_{i}\right)}{V_{Y Y}\left(Y_{i} ; A_{i}\right)}
$$

If the sign is negative, the return are decreasing (as assumed in the text) and vice versa. In order to evaluate the sign of the second order derivative of the financially constrained output function, therefore, one has to sign the third order derivatives of the objective function $V_{Y A Y}$ and $V_{Y Y Y}$. We do not have specific priors concerning the sign of these derivatives. However, $f^{\prime \prime}$ may be negative in a number of cases in which the signs of the third derivatives can be different. If the financially constrained output function is the same for all D firms, by Jensen's inequality an increase in the variance of financial conditions brings about a reduction of average (and therefore aggregate) output of D firms.

For simplicity we assume that the production function of each $\mathrm{D}$ firm is of the Leontief type: $Y_{i}=\min \left(\left(1 / \delta_{d}\right) N_{i},(1 / \gamma) Q_{i}\right)$ where $N_{i}$ is employment and $Q_{i}$ are intermediate inputs, $\delta_{d}>0$ and $\gamma>0$. Therefore, each D firm has the following labour and intermediate goods requirement functions: $N_{i t}=\delta_{d} Y_{i t}, Q_{i t}=\gamma Y_{i t}$. Taking into account (1), in the end, both the demand for labour and the demand for intermediate goods of $\mathrm{D}$ firms are increasing and concave functions of their financial conditions: $N_{i t}=\delta_{d} \phi A_{i t}^{\beta}$, $Q_{i t}=\gamma \phi A_{i t}^{\beta}$.

Final goods are sold at a stochastic price $u_{i t}$. For the sake of simplicity, we assume that $u_{i t}$ is a random variable uniformly distributed on the support $\left(u_{\min }, u_{\max }\right.$ ), where $0 \leq u_{\min }<1$ and $u_{\max }=2-u_{\min }$. We can provide the following rationale for this apparently restrictive assumption. Let the demand of the $i$ th commodity in period $t$ be $d\left(u_{i t}, \delta_{i t+1}\right)$ where $u_{i t}$ is the relative price of the $i$ th commodity and $\delta_{i t}$ is a stochastic demand disturbance specific to the market in question. Let supply be $s_{i t}$. By assumption $s_{i t}$ is made up of the quantities produced by a "large number" of producers so that the contribution of each firm to total supply is negligible. In equilibrium $u_{i t}=f\left(\delta_{i t}, s_{i t}\right)$, i.e. the relative price is an increasing function of the demand disturbance, given the predetermined supply. If demand is sufficiently elastic, changes in supply do not affect the relative price significantly so that the relative price is essentially an increasing function of random demand. A high realization of $u_{i t}$ can be thought of as a regime of high demand which drives up the relative price of the commodity in question. In a regime of low demand, the realization of $u_{i t}$ turns out to be low and may push the firm out of the market if it is "too low", i.e. if it makes the net worth of the firm negative.

Upstream firms produce the intermediate good by means of a linear technology which employs only labour: $Q_{j t}=\left(1 / \delta_{u}\right) N_{j t}$ where $\delta_{u}>0$. For simplicity, we assume an asymmetric structure of the D-U network: many D firms can be linked to a single $U$ firm but each D firm has only one supplier of intermediate goods.

In each period the supplier-say the $j$ th firm_receives orders from a set of D customers which will be denoted by $\Phi_{j}$. Since each D firm looks for the U firm with the lowest price of intermediate goods, by construction the number of elements of $\Phi_{j}$ depends on the price $p_{j t}$ that the upstream firm charges to its customers: the lower the price, the higher the number of $\mathrm{D}$ customers of the $j$ th supplier of intermediate goods.

The price the supplier is charging to the $i$ th $\mathrm{D}$ firm is defined as $p_{j t}^{i}=1+r_{j t}^{i}$ where $r_{j t}^{i}$ is the interest rate on trade credit. Therefore, in our framework, trade credit is mainly due to a transaction motive (Nilsen, 2002).

We assume that the level of $r_{j t}^{i}$ depends on the financial condition of the lender (U firm) and of the borrower (D firm) as follows:

$$
r_{j t}^{i}=\alpha A_{j t}^{-\alpha}+\alpha\left(l_{i t}\right)^{\alpha}
$$

where $\alpha>0$ and $l_{i t}$ is the $i$ th D firm's leverage, i.e. the ratio of commercial credit extended to the ith D firm to its net worth. In words, the interest rate on commercial paper charged to each and every D firm belonging to $\Phi_{j}$ is decreasing with the financial soundness of the $U$ firm and increasing with the leverage of the $\mathrm{D}$ firm.

Eq. (3) is an instance of the reduced form of a more general model for the interest rate charged by the lender-it will be adopted also later on, see the section on banks below-according to which the lender (i) will be eager to extend credit at 
more favourable terms to the borrower if the lender is in good shape from the financial point of view, and (ii) will charge a risk premium to the borrower whose magnitude depends on the borrower's financial soundness.

Point (i) captures the incentive for the lender to slash the interest rate in order to increase her market share in "prosperous times"-i.e. when the risk of default for the lender is low due to a high net worth-i.e. to adopt an aggressive marketing strategy. ${ }^{3}$ We will see shortly, in fact, that partner selection both on the market for trade credit and on the market for bank loans is endogenous in our framework and that borrowers tend to switch to lenders who extend credit at better terms.

Point (ii) captures the idea that, in an asymmetric information context, the lender requires an external finance premium to the borrower which depends of the latter's net worth (see for instance the optimal debt contract in Bernanke and Gertler (1989). Accordingly, the behaviour of $U$ firms in extending credit to D firms is similar to that of banks as we will see shortly (Mateut et al., 2006). ${ }^{4}$ The presence of an endogenous external finance premium in the interest rate on trade credit is one of the channels of the transmission and amplification of a shock through the credit network, i.e. of the network-based financial accelerator.

While the scale of production of D firms is financially constrained-i.e. it is determined by their degree of financial robustness - the scale of production of $U$ firms is demand constrained, i.e. it is determined by the demand of intermediate goods on the part of D firms. Therefore, the financial conditions of D firms are the driving force also for the production of $U$ firms. The more robust, on average, D firms, the higher their scale of activity and the demand for labour and intermediate goods so that the higher will be, on average, the scale of activity of $U$ firms. For instance, the demand of intermediate goods-and therefore the scale of production-of the $j$ th $U$ firm will be $Q_{j t}=\gamma \sum_{i \in \Phi_{j}} Y_{i t}=\gamma \phi \sum_{i \in \Phi_{j}} A_{i t}^{\beta}$ and the demand for labour will be $N_{j t}=\delta_{u} \gamma \phi \sum_{i \in \Phi_{j}} A_{i t}^{\beta}$.

\section{Banks}

Firms face a financing hierarchy in which internal finance ranks first and bank loans second. Therefore, by assumption, the financing gap, i.e. the difference between the firm's expenditures and internal finance, is filled by means of credit. For $U$ firms, the financing gap is the difference between the wage bill and net worth. As to D firms, expenditures consist of wages and the cost of intermediate goods. In order to keep the analysis as simple as possible, however, we assume that also for $\mathrm{D}$ firms the financing gap is the difference between the wage bill and net worth. This means that the acquisition of intermediate goods can be financed by means of trade credit, not by bank loans.

Accordingly, the demand of credit is equal to $B_{x t}=W_{x t}-A_{x t}$ where $W_{x t}=w N_{x t}$ is the firm's wage bill ( $x=i$ for D firms, $j$ for $U$ firms). We assume that the real wage $w$ is constant and uniform across firms. By assumption, moreover, labour is abundant so that firms do not face any labour shortage at the pre-determined real wage.

Self-financed firms, i.e. firms with a level of net worth sufficient to finance the wage bill, do not demand credit. From the expression above follows that the demand for credit of the $i$ th $\mathrm{D}$ firm is

$$
B_{i t}=w N_{i t}-A_{i t}=w \delta_{d} \phi A_{i t}^{\beta}-A_{i t}
$$

so that a $\mathrm{D}$ firm is self-financed if it has net worth $A_{i t} \geq \hat{A} \equiv\left(w \delta_{d} \phi\right)^{1 /(1-\beta)}$.

As to $U$ firms, the demand for credit of the $j$ th $U$ firm is

$$
B_{j t}=w N_{j t}-A_{j t}=w \delta_{u} \gamma \phi \sum_{i \in \Phi_{j}} A_{i t}^{\beta}-A_{j t}
$$

so that a $U$ firm is self-financed if it has net worth $A_{j t} \geq \hat{A}_{j} \equiv w \delta_{u} \gamma \phi \sum_{i \in \Phi_{j}} A_{i t}^{\beta}$. The higher the net worth of $D$ customers of the U firm, the less likely it is that the $U$ firm will be self-financed.

For simplicity, we assume an asymmetric structure of the firms-banks network: many firms can be linked to a single bank but each firm has only one supplier of loans. The set of customers of the $z$ th bank will be denoted by $\Phi_{z}$. We assume that each bank has a certain degree of market power. Since each firm looks for the bank with the lowest interest rate, by construction the number of elements of $\Phi_{z}$ depends on the interest rate the bank charges to its customers: the lower the interest rate, the higher the number of firms applying for loans to the $z$ th bank.

The $z$ th bank adopts the following rule in setting the interest rate on loans to the $x$ th borrower ( $x=i$ for D firms, $j$ for $U$ firms):

$$
r_{z t}^{x}=\alpha A_{z t}^{-\alpha}+\alpha\left(l_{x t}\right)^{\alpha}
$$

where $A_{z t}$ is the net worth of the $z$ th bank and $l_{x t}=B_{x t} / A_{x t}$ is the leverage ratio of the $x$ th firm.

Accordingly, the interest rate on bank loans is decreasing with the financial soundness of the bank (proxied by the bank's net worth $A_{z t}$ ) and increasing with the firms' leverage ratio.

\footnotetext{
${ }^{3}$ In a sense, trade credit is an investment that, like expenditures in advertising, by trying to establish a long-term relationship between the lender (seller) and the borrower (buyer), yields a long term return (Nadiri, 1969). "In particular trade credit extension can be used as a many-faceted marketing/ relationship management tool and/or as a means of signalling information to the market or to specific buyers about the firm, its product, its financial health, and its future prospects/commitments to the industry" (Summers and Wilson, 2003, p. 439).

${ }^{4}$ A similar interpretation is that $\mathrm{U}$ firms charge to borrowers a risk premium due to costly state verification as in Boissay (2006).
} 
We have pointed out before that this is a general principle: if the bank is in good shape from the financial point of view, it will be eager to extend credit at more favourable terms to increase her market share. Moreover, the interest rate charged by the bank incorporates an external finance premium increasing with borrower's leverage.

As in the case of $U$ firms, financially sound banks extend credit at more favourable conditions to attract new customers. In an asymmetric information framework, this attitude depends on the quality of banks' assets (in our case, this is proxied by the level of net worth) which acts as a signal on the loan market and allows financially sound banks to set interest rates lower than those fixed by low-capitalized ones. ${ }^{5}$ In other words, when banks have partial knowledge of loan quality and the market for bank debt is imperfect (Kashyap and Stein, 1995, 2000; Stein, 1998; Kishan and Opiela, 2000), it raises an asymmetric information problem about banks' assets and a lemon's premium is paid to investors (Gambacorta, 2008). ${ }^{6}$ At the same time, banks charge a risk (external finance) premium to firms depending on their leverage (Bernanke and Gertler, 1989), as in the case of U firms vs. D firms described above. The presence of an endogenous external finance premium in the interest rate on bank loans is another channel of the network-based financial accelerator.

Notice that the leverage ratio of the $i$ th $\mathrm{D}$ firm is

$$
l_{i t}=B_{i t} / A_{i t}=w \delta_{d} \frac{Y_{i t}}{A_{i t}}-1=w \delta_{d} \phi A_{i t}^{-(1-\beta)}-1
$$

i.e. it is decreasing with net worth. Therefore, in the end, the interest rate charged by the $z$ th bank to the $i$ th $\mathrm{D}$ firm will be

$$
r_{z t}^{i}=\alpha A_{z t}^{-\alpha}+\alpha\left(w \delta_{d} \phi A_{i t}^{-(1-\beta)}-1\right)^{\alpha}
$$

i.e. it will be a decreasing function of the net worth of the bank and of the firm.

The situation is different in the case of $U$ firms. The leverage of the $j$ th $U$ firm is

$$
l_{j t}=B_{j t} / A_{j t}=w \delta_{u} \frac{Q_{j t}}{A_{j t}}-1=\frac{w \delta_{u} \gamma \phi}{A_{j t}} \sum_{i \in \Phi_{j}} A_{i t}^{\beta}-1
$$

since $Q_{j t}=\gamma \phi \sum_{i \in \Phi_{i}} A_{i t}^{\beta}$ as shown above. The leverage of $U_{j}$ firm therefore is decreasing with its own net worth but increasing with the net worth of the downstream customers.

The interest rate charged by the $z$ th bank to the $j$ th $U$ firm will be

$$
r_{z t}^{j}=\alpha A_{z t}^{-\alpha}+\alpha\left(\frac{w \delta_{u} \gamma \phi}{A_{j t}} \sum_{i \in \Phi_{j}} A_{i t}^{\beta}-1\right)^{\alpha}
$$

i.e. it will be a decreasing function of the net worth of the bank and of the jth firm but an increasing function of the net worth of the D customers. This may be counterintuitive but it is obvious in our context: the higher the net worth of $\mathrm{D}$ customers, the higher their demand for intermediate goods, the higher the debt-and therefore the leverage ratio, other things being equal-that $U$ suppliers have to accept in order to finance the wage bill and production and the higher the interest rate charged by the bank to the U-firm.

\section{Partner's selection}

Each borrower has to choose the lender to establish a credit relationship with: a D firm has to choose a U firm and a bank; a U firm has to choose a bank. ${ }^{7}$

Initially, at time $t=1$, the credit network is random, i.e. the links among $\mathrm{D}$ and $\mathrm{U}$ firms, and among firms and banks, are established at random. From $t=2$ on, in every period each borrower observes the interest rates of a randomly selected number of potential lenders - say a fraction $M$ of the total population of lenders. We assume that the borrower sticks to the current lender if the previous partner's interest rate, $r_{\text {old }}$, is smaller or equal than the minimum interest rate set by the observed potential new partners, $r_{\text {new }}$. If this is not the case, the probability $p_{s}$ of switching to a new lender is decreasing (in a non-linear way) with the difference between $r_{\text {old }}$ and $r_{n e w}$. In symbols:

$$
\begin{cases}p_{s}=1-e^{\lambda\left(r_{\text {new }}-r_{\text {old }}\right) /\left(r_{\text {new }}\right)} & \text { if } r_{\text {new }}<r_{\text {old }} \\ 0 & \text { otherwise }\end{cases}
$$

\footnotetext{
${ }^{5}$ In a sense, this is similar to the context described by Lucas and McDonald (1992) according to which, if banks' assets are observable, banks may hold T-bills to signal their quality, enabling them to issue risky debt at a lower interest rate.

${ }^{6}$ In this setting, "small, low liquid, and low-capitalized banks pay a higher premium because the market perceives them to be more risky. Since these banks are more exposed to asymmetric information problems they have less capacity to shield credit relationships in the case of a monetary tightening, and they should cut their their supplied loans and raise the interest rate by a larger amount" (Gambacorta, 2008, p. 798). The effects of monetary policy changes and the functioning of monetary transmission mechanisms in a credit-network economy would be an interesting topic to be analyzed in a future extension of the present work.

7 The intermediate goods' prices charged by U firms to D firms in fact depend exclusively on the interest rates charged on trade credit.
} 
where $\lambda>0$ is an "intensity of choice" parameter. Therefore, the number of links among agents changes over time due to the changing interest rate charged by the $U$ firms or banks so that the topology of the network is also in a process of continuous evolution. The total number of nodes, however, is constant.

This procedure to choose the partner is activated in every period-i.e. with the same frequency as that of price/quantity decisions - but the partner is changed less frequently, i.e. only when one of the interest rates the borrower observes is lower than the one charged by the current lender. By construction, therefore, the relationships between firms of different industries and between firms and banks last longer than one period.

When a negative shock hits a node-for instance a firm goes bankrupt — the lenders of the bankrupt firm react by raising the interest rate charged to all the other borrowers (see above, Eqs. (4) and (5)). According to the partner's selection mechanism, this interest rate hike may induce the latter to switch to lenders who offer more favourable conditions, thereby attenuating the fallout of the shock. Hence the partner selection mechanism may mitigate the spreading and amplification of the "disease", i.e. it may slow down the financial accelerator.

In the literature on networks, the choice of the partner is sometimes governed by preferential attachment (Barabàsi and Albert, 1999), which is based on the assumption that nodes characterized by a relatively high number of links ("hubs") attract more new partners than nodes with a small number of connections. As a consequence, the degree distribution of the network is power law. Preferential attachment plays the role of a self-reinforcing mechanism: the higher the number of links of a certain node today, the higher will be the number of new links attached to that node tomorrow.

We do not make this ad hoc assumption here but a similar outcome occurs in our model due to the matching mechanism explained above. Lenders characterized by more robust financial conditions, in fact, can charge lower prices and therefore attract more new partners. As a consequence, their profits go up and their financial conditions improve, making room for even lower prices in the future and attracting more new partners. In a sense the process of partner selection operating in our model makes preferential attachment endogenous, through a mechanism similar to that described in physics as the fitness model (Bianconi and Barabàsi, 2001). In general, we follow a "strategic link formation" approach (Jackson, 2008), which broadly derives from "evolutionary game theory" models (Vega-Redondo, 2007) and gives rise to an endogenous evolution of the credit network.

\section{Profits}

The profit of the $i$ th $\mathrm{D}$ firm is $\pi_{i t}=u_{i t} Y_{i t}-\left(1+r_{z t}^{i}\right) B_{i t}-\left(1+r_{j t}^{i}\right) Q_{i t}$ where $u_{i t}$ is the stochastic price, $Y_{i t}$ is output, $r_{z t}^{i}$ is the interest rate charged by $B_{z}$ to $D_{i}, r_{j t}^{i}$ is the interest rate charged by $U_{j}$ to $D_{i}$, and $Q_{i t}$ is the amount of intermediate input that $D_{i}$ has bought from $U_{j}$.

Recalling that $Q_{i t}=\gamma Y_{i t}$, output is financially constrained as shown in (1) and $B_{i t}$ is defined as in (4) we can rewrite the equation above as

$$
\pi_{i t}=\left[u_{i t}-\left(1+r_{j t}^{i}\right) \gamma-\left(1+r_{z t}^{i}\right) w \delta_{d}\right] \phi A_{i t}^{\beta}+\left(1+r_{z t}^{i}\right) A_{i t}
$$

Since $r_{z t}^{i}$ and $r_{j t}^{i}$ are defined as in (8) and (3), respectively, in the end $D_{i}$ 's profit is a function of its own net worth and of the net worth of the $U$ firm and of the bank.

Other things being equal, an increase of $A_{i t}$ affects $D_{i}$ 's profit for three reasons:

- it makes output increase (scale effect);

- it makes leverage decrease so that the interest rate charged by the bank decreases too ( $D$ leverage effect);

- it makes the financing gap decrease. This effect is captured by the last term in the RHS of (11) (financing gap effect).

The scale effect can be either positive (if the expression in brackets is positive, i.e. if the relative price is "sufficiently high" or the interest rates are "sufficiently low") or negative (if the opposite holds true). The D leverage and the financing gap effects are unambiguously positive.

$D_{i}$ 's profit is also affected by the financial conditions of the $U$ supplier and of the bank through the following externalities:

- an increase of $A_{j t}$ makes $D_{i}$ 's profit increase because it makes the interest rate charged by the supplier go down ( $U$ net worth effect);

- an increase of $A_{z t}$ makes $D_{i}$ 's profit increase because it makes the interest rate charged by the bank go down ( $B$ net worth effect).

The profit of the $j$ th upstream firm is $\pi_{j t}=\sum_{i \in \phi_{j}}\left(1+r_{j t}^{i}\right) Q_{j t}-\left(1+r_{z t}^{j}\right) B_{j t}$. Notice that $Q_{j t}=\gamma \phi \sum_{i \in \Phi_{j}} A_{i t}^{\beta}$, and $B_{j t}$ is defined as in (5) so that in the end we get

$$
\pi_{j t}=\sum_{i \in \Phi_{j}}\left[\left(1+r_{j t}^{i}\right)-\left(1+r_{z t}^{j}\right) w \delta_{u}\right] \gamma \phi A_{i t}^{\beta}+\left(1+r_{z t}^{j}\right) A_{j t}
$$


Table 1

The effects of net worth on profit.

\begin{tabular}{lll}
\hline & $\pi_{i}$ & $\pi_{j}$ \\
\hline$A_{i}$ & $\begin{array}{l}\text { Scale e. }( \pm) \\
\text { D leverage e. }(+) \\
\text { D fin.gap e. }(+)\end{array}$ & Scale e. $( \pm)$ \\
$A_{j}$ & U net worth e. $(+)$ & D leverage e. $(-)$ \\
& & U net worth e. $(-)$ \\
$A_{z}$ & B leverage e. $(+)$ & U fin.gap e. $(+)$ \\
Bank's net w.e. $(+)$
\end{tabular}

Accordingly, $U_{j}$ 's profit is a function of the net worth of the agents involved, i.e. the $U$ firm itself, the set $\Phi_{j}$ of its $\mathrm{D}$ customers and the bank.

An increase of $A_{j t}$ affects $U_{j}$ 's profit for three reasons:

- it makes $U_{j}$ 's leverage decrease, so that the interest rate charged by the bank decreases too ( $U$ leverage effect);

- it makes the financing gap decrease. This effect is captured by the last term in the RHS of (12) (financing gap effect);

- it makes the price charged to D customers decrease (U net worth effect).

The $U$ leverage and the financing gap effects are positive while the $U$ net worth effect is negative.

$U_{j}$ 's profit is also affected by the financial conditions of $\mathrm{D}$ customers and of the bank through the following externalities:

- an increase of $A_{z t}$ makes $U_{j}$ 's profit increase because it makes the interest rate charged by the bank go down ( $B$ net worth effect);

- an increase of the net worth of the D customers $\sum_{i \in \Phi_{j}} A_{i t}^{\beta}$ affects U output (scale effect).

The bank's B net worth effect is positive while the scale effect can be either positive (if the expression in brackets is positive, i.e. if the interest rate on trade credit is "sufficiently high" and/or the interest rate on bank loans is "sufficiently low") or negative (if the opposite holds true).

The profit of the $z$ th bank is

$$
\pi_{z t}=\sum_{i \in I_{z}}\left(1+r_{z t}^{i}\right) B_{i t}+\sum_{j \in J_{z}}\left(1+r_{z t}^{j}\right) B_{j t}
$$

where $I_{z}$ and $J_{z}$ are, respectively, the set of D and U firms interacting with bank $z$. $^{8}$ Substituting (4) and (5) we get

$$
\pi_{z t}=\sum_{i \in I_{z}}\left(1+r_{z t}^{i}\right)\left(w \delta_{d} \phi A_{i t}^{\beta}-A_{i t}\right)+\sum_{j \in J_{z}}\left(1+r_{z t}^{j}\right)\left(w \delta_{u} \gamma \phi \sum_{i \in \Phi_{j}} A_{i t}^{\beta}-A_{j t}\right)
$$

An increase of $A_{z t}$ affects $B_{z}$ 's profit for the simple reason that it makes the interest rate charged by the bank to both $\mathrm{D}$ and $U$ firms go down ( $B$ net worth effect).

$B_{z}$ 's profit is also affected by the financial conditions of $\mathrm{D}$ and $\mathrm{U}$ borrowers through the following externalities:

- an increase of the net worth of $D$ and $U$ borrowers affects $B_{z}$ 's profit because it makes their leverage decrease so that the interest rate charged by the bank to these borrowers, i.e. $r_{z t}^{i}$ and $r_{z t}^{j}$ go down ( $D$ leverage and $U$ leverage effects);

- an increase of the net worth of $U$ borrowers affects $B_{z}$ 's profit because it makes the volume of loans to $U$ customers decrease (U scale effect);

- an increase of $D_{i}$ 's net worth makes the volume of loans to U customers increase while the volume of loans to D customers increases only if $\left(w \delta_{d} \phi \beta\right)^{1 /(1-\beta)}>A_{i t}$, i.e. if the firm is not self-financed ( $D$ scale effect).

Table 1 summarizes the effects of net worth of each type of agent on the profit of the same agent (on the main diagonal) and on the profits of the other agents (externalities, represented by off diagonal entries).

As will become clear in the following section, profits are an important determinant of the flow of new net worth: the higher profits today, the higher will be net worth tomorrow. Table 1 therefore provides a rich and complicated picture of interactions among the financial conditions of the agents involved $\left(D_{i}, U_{j}, B_{z}\right)$.

For instance, the first column represents the impact of an increase of net worth of $D_{i}, U_{j}, B_{z}$ on $D_{i}$ 's profits. There are obvious self-reinforcing mechanisms at work. If the net worth of $D_{i}$ is growing, it is likely to grow bigger in the future due

\footnotetext{
${ }^{8}$ Of course $I_{z} \cup J_{z}=\Phi_{z}$.
} 
to the D leverage and D financing gap effects. $D_{i}$ can also benefit, in terms of profits and net worth accumulation, from an increase of $U_{j}$ 's and $B_{z}$ 's net worth, due to the $U$ and B net worth effects.

There are, however, also self-stabilizing mechanisms, which work mainly through the banking system. An increase of $U_{j}$ 's and $D_{i}$ 's net worth, for instance, tends to depress the accumulation of the bank's net worth due to the leverage effect and the $U$ scale effect. The co-existence of self-reinforcing and self-stabilizing mechanisms is the source of the oscillating behaviour of aggregate time series generated by the simulations that we will review in Section 8 .

\section{Bad debt and net worth}

In our framework, the U firms and the banks are lenders while both types of firms can be borrowers (if they are not selffinanced).

D firms therefore are pure borrowers. At the end of the period, the net worth of the ith D firm is defined as follows:

$$
A_{i t+1}=A_{i t}+\pi_{i t}
$$

i.e. profits are the flow of new net worth. The $\mathrm{D}$ firm goes bankrupt if $A_{i t+1} \leq 0$, i.e. if it incurs a loss (negative profit) and the loss is big enough to deplete net worth:

$$
\pi_{i t} \leq-A_{i t}
$$

The net worth of D firms is the "engine" of fluctuations for the entire economy. In fact, by means of (1) $D_{i}$ 's net worth determines $D_{i}$ 's output, which in turn generates the demand for intermediate goods produced by U firms. As a consequence also the demand for labour of the $\mathrm{D}$ and $\mathrm{U}$ firms are determined by the net worth of $\mathrm{D}$ firms.

Substituting (11) into (14) we get

$$
A_{i t+1}=A_{i t}+\left[u_{i t}-\left(1+r_{j t}^{i}\right) \gamma-\left(1+r_{z t}^{i}\right) w \delta_{d}\right] \phi A_{i t}^{\beta}+\left(1+r_{z t}^{i}\right) A_{i t}
$$

The net worth of the $\mathrm{D}$ firm in $t+1 A_{i t+1}$ depends in a non-linear way on $A_{i t}$ but also on the net worth of the $U$ supplier - which determines $r_{j t}^{i}$ as defined in (3) -and on the net worth of the bank, which enters into (8).

The net worth of the $x$ th lender ( $x=j$ for U firms, $z$ for banks) is defined as follows:

$$
A_{x t+1}=A_{x t}+\pi_{x t}-B D_{x t}
$$

where $B D_{x t}$ is "bad debt". In fact, if a borrower cannot pay back the loan obtained from the lender and goes bankrupt, the lender has a bad debt (non-performing loan), that is accounted for as a reduction of its net worth. The lender goes bankrupt if $A_{x t+1} \leq 0$, i.e. if

$$
\pi_{x t}+A_{x t} \leq B D_{x t}
$$

In principle therefore, the lender can go bankrupt even profits are still positive if non-performing loans are high enough to wipe out net worth.

Substituting (12) into the definition, $U_{j}$ 's net worth turns out to be

$$
A_{j t+1}=A_{j t}+\sum_{i \in \Phi_{j}}\left[\left(1+r_{j t}^{i}\right)-\left(1+r_{z t}^{j}\right) w \delta_{u}\right] \gamma \phi A_{i t}^{\beta}+\left(1+r_{z t}^{j}\right) A_{j t}-B D_{j t}
$$

In the case of $U$ firms, bad debt is $B D_{j t}=\sum_{i \in \Phi^{B}}\left(1+r_{j t}\right) \gamma Y_{i t}$, i.e. the amount of trade credit not reimbursed (intermediate goods not paid for) by bankrupt D customers, which are grouped for convenience in the set $\Phi_{j}^{B}$. The net worth in $t+1 A_{j t+1}$ depends in a non-linear way on $A_{j t}$ but also on the net worth of the $\mathrm{D}$ customers, which determines output of the $\mathrm{U}$ firm and bad debt (the set of bankrupt firms is a subset of D customers of the U supplier)—and on the net worth of the bank, which enters into (10).

Substituting (13) into the definition, the net worth of the bank turns out to be

$$
A_{z t+1}=A_{z t}+\sum_{i \in I_{z}}\left(1+r_{z t}^{i}\right)\left(w \delta_{d} \phi A_{i t}^{\beta}-A_{i t}\right)+\sum_{j \in J_{z}}\left(1+r_{z t}^{j}\right)\left(w \delta_{u} \gamma \phi \sum_{i \in \Phi_{j}} A_{i t}^{\beta}-A_{j t}\right)-B D_{z t}
$$

In the case of banks, "bad debt" is $B D_{z}=\sum_{i \in \Phi_{2}^{B}}\left(1+r_{z t}^{i}\right) B_{i t}+\sum_{j \in \Phi_{z}^{B}}\left(1+r_{z t}^{j}\right) B_{j t}$, i.e. non-performing loans of bankrupt $\mathrm{D}$ and $\mathrm{U}$ firms, which are grouped for convenience in the set $\Phi_{z}^{B}$. The net worth of the D and U borrowers co-determines the evolution over time of $A_{z t+1}$.

The bankruptcy of a borrower creates a negative externality because the bad debt recorded on the lender's balance sheet yields an increase of the interest rate charged to all the other borrowers. This is the starting point of the financial accelerator. If the surviving borrowers experience an increase of leverage due to the interest rate hike, the lender will react by raising the interest rate even further (see Eqs. (4) and (5)). Financial fragility will spread to the neighbourhood and may spill over to the entire economy. An avalanche of bankruptcies may ensue. This is, in a nutshell, the way in which the network-based financial accelerator amplifies a shock. 
Table 2

Parameter setting.

\begin{tabular}{|c|c|}
\hline Financially constrained output of D firms & $\phi=2 ; \beta=0.9$ \\
\hline Lower bound for stochastic prices & $u_{\min }=0.5$ \\
\hline Labour requirement of $\mathrm{D}$ and $\mathrm{U}$ firms & $\delta_{d}=0.5 ; \delta_{u}=1$ \\
\hline Intermediate goods requirement of D firms & $\gamma=0.5$ \\
\hline Interest rate setting & $\alpha=0.01$ \\
\hline Real wage & $w=1$ \\
\hline Partner choice & $\lambda=1$ \\
\hline Number of potential partners & $M=10 \%$ \\
\hline
\end{tabular}

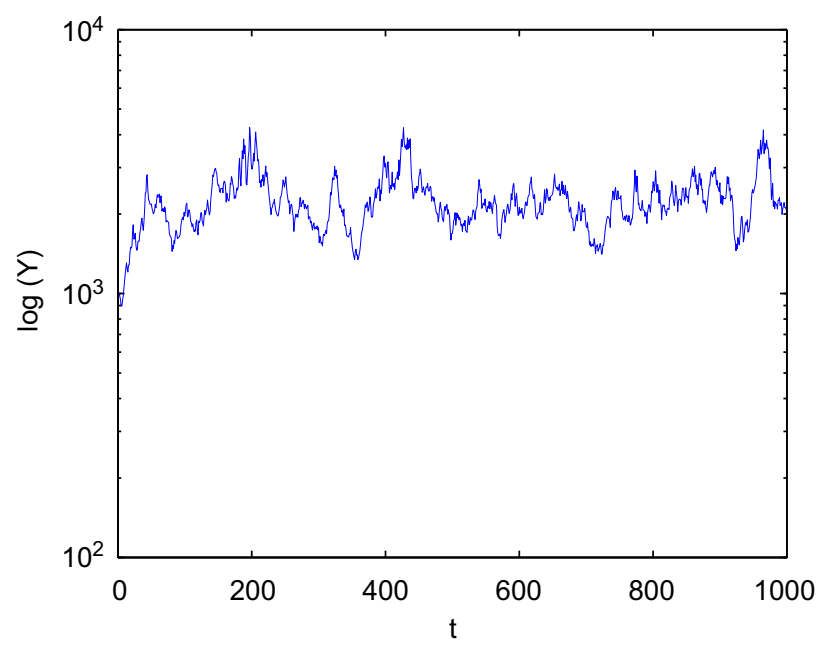

Fig. 1. Aggregate production.

\section{Simulations}

We explore the dynamic properties of the network economy modelled above by means of computer simulations. We consider an economy consisting of $I=500 \mathrm{D}$ firms, $J=250 \mathrm{U}$ firms and $Z=100$ banks over a time span of $T=1000$ periods. The net worth of each $\mathrm{D}$ and $\mathrm{U}$ firm and of each bank at the beginning of the time horizon is set to 1 . Furthermore, we assume a simple mechanism of entry-exit: bankrupt firms/banks are replaced with new entrants on the basis of a one-to-one replacement. ${ }^{9}$

First we simulate the baseline version of the model using the parameter values reported in Table 2 . We do not carry on a validation exercise on empirical data because our framework does not allow for essential features of a real world economy such as investment in capital goods, inventories, innovation and technological progress, realistic labour market and wage dynamics, etc. We have simplified or neglected these features to focus on credit interactions and financially constrained fluctuations. However, we chose a configuration of parameters which yields in the simulated data some well known empirical regularities such as the negative skewness and the leptokurtosis of the distribution of aggregate growth rates. In Section 8.1 we compare the output of simulation of the baseline model when the choice of the partner is endogeneous with the properties of the same model for a random matching mechanism. In Sections 8.2 and 8.3 we will perform some robustness checks and a sensitivity analysis of simulation results.

Fig. 1 shows the time series of aggregate D production obtained by adding up the production of D firms. Aggregate $U$ production follows the same dynamic pattern since $U$ suppliers produce intermediate goods for D production "on demand". As expected, in a complex adaptive system fluctuations are irregular. Amplitude and periodicity vary wildly from sub-period to sub-period.

Starting from identical initial conditions firms become rapidly heterogeneous. ${ }^{10}$ Over time, a right-skew distribution of firms' size emerges (see Fig. 2). Once again this is not surprising since the economy we are considering is characterized by heterogeneous interacting agents.

\footnotetext{
${ }^{9}$ Accordingly, the total number of agents in the economy is constant over time. New agents are endowed with an initial amount of net worth drawn from a uniform distribution with mean 1 and finite variance. We assume the entrant is small relative to the size of the incumbent firms.

${ }^{10}$ In each period, each D firm is hit by a price shock because the relative price is stochastic as explained in Section 2 . Therefore the accumulation of net worth on the part of each D firm rapidly takes different routes. The accumulation of net worth on the part of $U$ firms and banks is determined as a consequence. Neither U firms nor banks, however, are subject to individual shocks.
} 


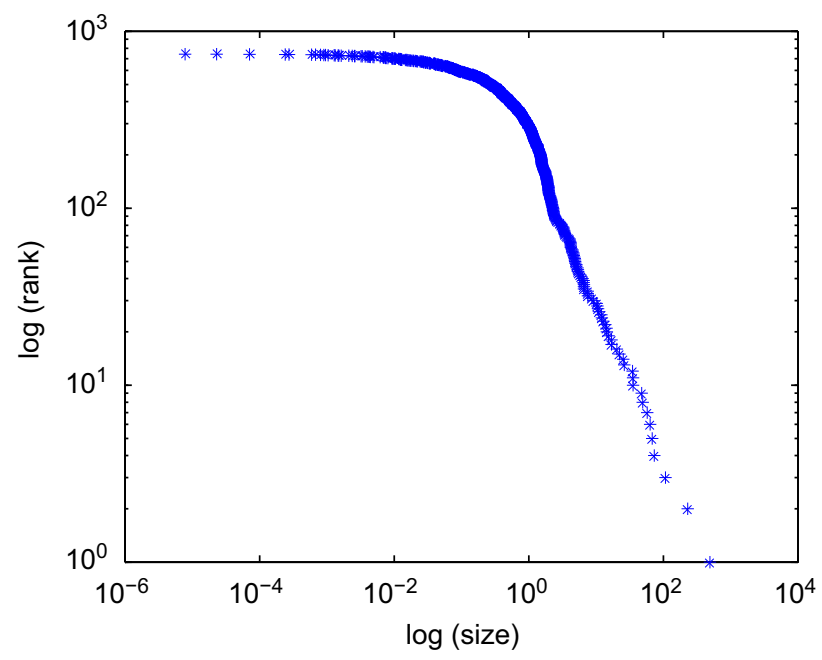

Fig. 2. Firms size distribution (in terms of net worth).

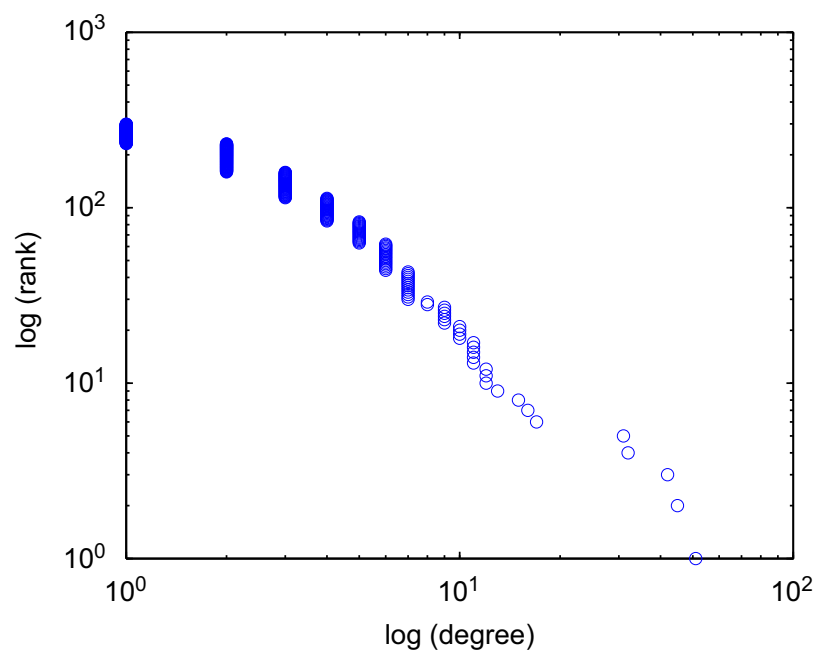

Fig. 3. Degree distribution of the network.

In addition, the distribution of the number of links (connectivity) for each lender (U firm or bank) becomes asymmetric over time due to the endogeneous mechanism of partner choice governing the interaction among borrowers and lenders. In other words, the degree distribution of the credit network suggests that the number of customers of lenders in the right tail of the distribution is higher than that generated by a normal distribution (see Fig. 3).

In general, financially robust lenders can supply credit at better conditions and therefore increase their market share, i.e. attract a higher number of links. Financially sound U firms (resp. banks) set lower prices (interest rates), attract more D firms (borrowers), are more profitable and further increase their financial robustness. The opposite holds true for financially fragile lenders. Both the corporate and the banking sector therefore become polarized and the degree distribution becomes asymmetric. In principle this polarization increases the vulnerability of the network to a shock-i.e. systemic risk - because the default of a highly connected agent, albeit a relatively rare event, may generate an avalanche of bankruptcies. The likelihood of this phenomenon depends on the structure of the network.

A typical story is the following. Suppose that $D_{i}$ belonging to $\Phi_{j}$ does not fulfill its debt obligations towards $U_{j}$ and goes bankrupt in $t$. $U_{j}$ will record a non-performing loan equal to the value of the intermediate goods not paid for by $D_{i}$ so that its net worth will go down next period. If $U_{j}$ were already fragile and/or the loan extended to $D_{i}$ were big, $U_{j}$ would go bankrupt in $t+1$. If it survives the shock, the reduction in net worth will lead the bank to charge a higher interest rate $r_{z t+1}^{j}$ due to the $U$ leverage and $U$ financing gap effect. Therefore also $U_{j}$ can go bankrupt in one of the following periods.

The deterioration of the bank's financial condition due to the borrowers' bankruptcies may be absorbed if the size of the loans is small enough and/or the bank's net worth is high enough. If this is not the case, also the bank goes bankrupt. 


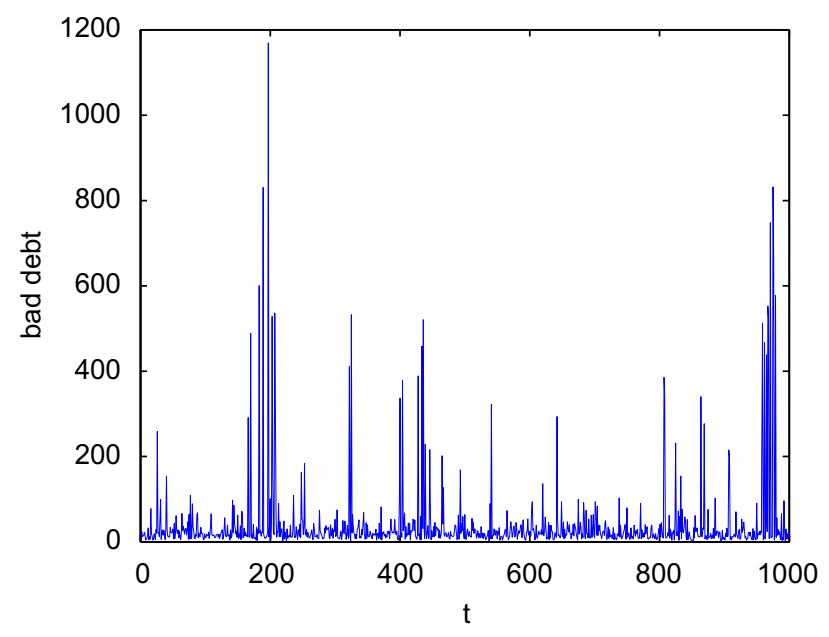

Fig. 4. The time evolution of bad debt.

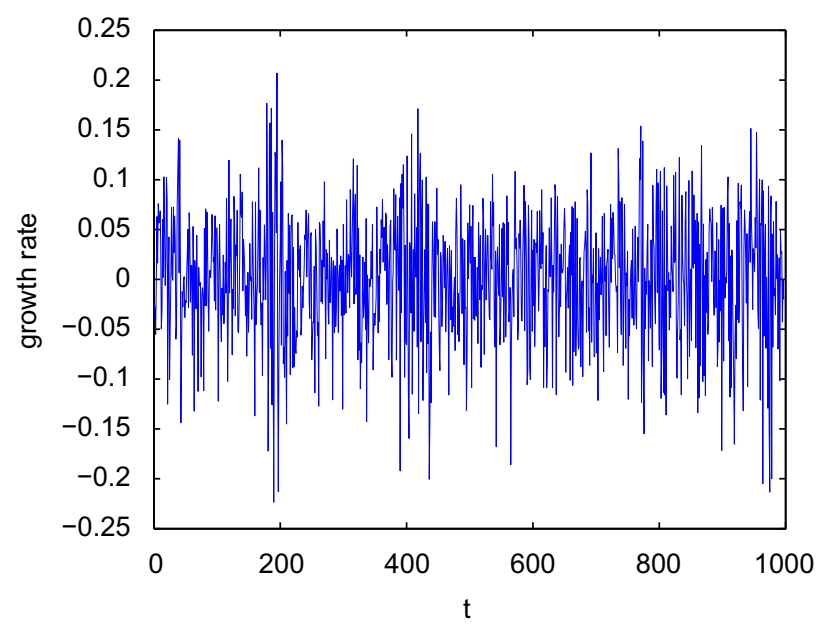

Fig. 5. The time evolution of aggregate growth rate.

An avalanche of bankruptcies will follow due to the positive feedback of the bankruptcy of a single agent on the net worth of the "neighbours", linked to the bankrupt agent by trade or credit links. ${ }^{11}$ The extent of bankruptcy avalanches depends on the amount of bad debt (see Fig. 4). Bankruptcy avalanches amplify business fluctuations: as a consequence, the distribution of aggregate growth rates is far from Gaussian, being characterized by negative skewness and excessive kurtosis (see Fig. 5). ${ }^{2}$

Simulation results highlight the interplay between microeconomic shocks and macroeconomic dynamics stressing the relevance of financial factors (Bruneau et al., 2008, provide an empirical analysis of these aspects): the financial fragility of agents affects the business cycle (Bernanke and Gertler, 1989; Lown and Morgan, 2006) which in turn influences agents' financial conditions (Allen and Saunders, 2004; Misina et al., 2006). In other words, a macroeconomic shock (or a given distribution of idiosyncratic shocks) affects the financial conditions of firms and banks; then, financial fragility amplifies the effect of the initial shock (in our case, we refer to this phenomenon as the network-based financial accelerator), giving rise to "second round effects". ${ }^{13}$ In the following, we will analyze statistical results coming from simulations to assess their robustness and to analyze the effects of parameters' changes on model behaviour.

\footnotetext{
${ }^{11}$ For empirical evidence on this phenomenon see Fujiwara (2008) and Fujiwara et al. (2009).

12 See Fagiolo et al. (2008) for an empirical investigation of the distributional properties of aggregate output growth-rate time series.

13 Using Swedish data over the period 1994-2000, Carling et al. (2007) estimate a model which takes into account both firm-specific characteristics and macroeconomic conditions: they find out that the output gap, the yield curve and consumers' expectations have significant explanatory power for the default risk of firms. Similar results are reached by Bruneau et al. (2008) using French data over the period 1990-2006: according to these authors the agents' bankruptcy rate (as an indicator of financial conditions) has a significant impact on the business cycle; at the same time, business cycle has a relevant influence on bankruptcies.
} 


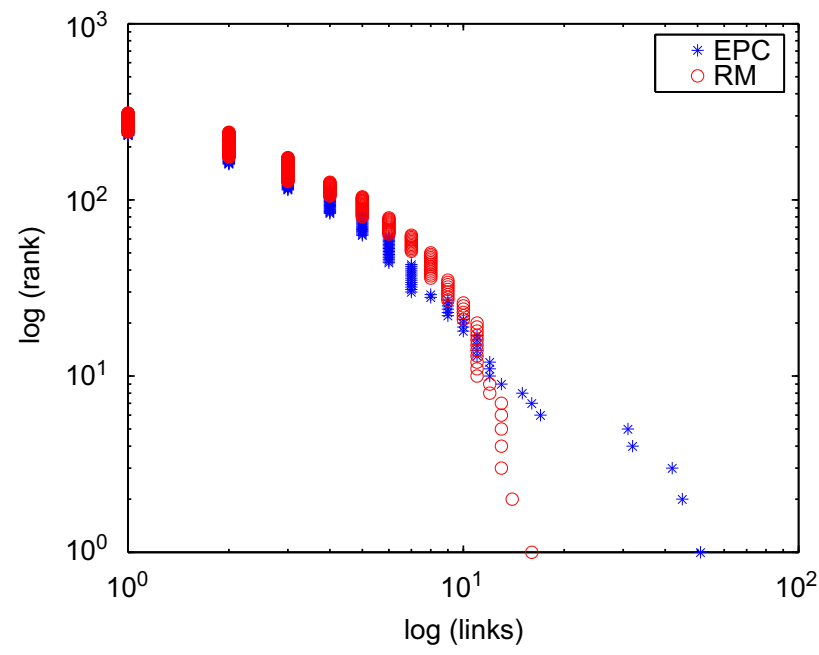

Fig. 6. Degree distribution of the network: EPC vs. RM.

\subsection{Endogeneous partner choice vs. random matching}

In order to assess the robustness of our findings, we perform a series of 100 Monte Carlo (MC) simulations in the two following alternative scenarios:

- endogeneous partner choice (EPC);

- random matching (RM).

In the RM case the interaction among agents is no longer due to the endogenous process described above; in each period, instead, each agent interacts with another agent picked at random in the population of potential partners.

Fig. 6 shows the degree distributions of the evolving (EPC) and the random (RM) networks. When the EPC rule is at work the degree distribution is right-skew while this is not the case if the network evolves according to a random matching.

In Table 3 we report some statistics (mean, median, standard deviation, median absolute deviation-denoted by the acronym "mad"-, skewness and kurtosis) characterizing the distribution of aggregate growth rates (GR), bad debt (BD), firms size (FSD), network degree (NDD). Moreover we report the correlation of defaults across sectors and bankruptcy probabilities. Since distributions are generally non-normal, we use robust statistics: in particular, we compute robust measures of skewness (Groeneveld and Meeden, 1984) and kurtosis (Moors, 1988). ${ }^{14}$ For each statistics we report the average value and the standard deviation (in parenthesis) across MC simulations.

In both scenarios the distribution of GR is left-skew and leptokurtotic. Also the median of aggregate bad debt (BD)-that is the sum of the bad debt of upstream firms and banks-and BD skewness and kurtosis are quite similar in the two settings. ${ }^{15}$ The high levels of skewness and kurtosis signal the presence of a right-skew distribution of BD with a relevant role for "extreme values" in both scenarios. On the other hand, the volatility of BD, as measured by the median absolute deviation, is higher in EPC than in RM.

In both scenarios the firm size distribution (FSD) is right-skew with high kurtosis and clearly different from the normal distribution. Skewness and kurtosis of NDD are higher in the EPC case than in the RM one. In the end, the endogeneous partner selection mechanism "makes a difference" (with respect to random matching) essentially in increasing the volatility of bad debts and in shaping the credit network's degree distribution.

We turn now to bankruptcy related statistics. In our setting, the default of one or more agents in a sector can propagate to the rest of the economy through the deterioration of financial conditions, increasing the likelihood of bankruptcy avalanches. In order to investigate this issue, we compute the correlation between the number of bankruptcies in different sectors and the default probability for different groups of agents.

\footnotetext{
14 The robust measure of skewness is: $S K=\left(\mu-Q_{2}\right) / E\left|y_{t}-Q_{2}\right|$, where $y_{t}$ represents the data, $\mu$ is the mean, and $Q_{2}$ is the median. The SK statistic has zero value for Gaussian data; the lower bound is -1 and the upper bound is +1 . The robust measure of kurtosis is: $K R=\left[\left(E_{7}-E_{5}\right)-\left(E_{3}-E_{1}\right)\right] /\left(E_{6}-E_{2}\right)-1.23$ where $E_{i}$ is the $i$-octile of the distribution and 1.23 is the value of KR for a normal distribution $\mathrm{N}(0,1)$. Accordingly, KR is equal to zero in the case of Gaussian data.

${ }^{15}$ In this case we do not report "traditional" measures, because of the relevant discrepancies, for example, between the mean and the median or the standard deviation and the median absolute deviation. We report only robust statistics which are more accurate in describing highly asymmetric nonnormal distributions.
} 
Table 3

Monte Carlo simulations: EPC vs. RM.

\begin{tabular}{|c|c|c|}
\hline & $E P C$ & $R M$ \\
\hline Mean(GR) & $0.0010(0.0000)$ & $0.0010(0.0000)$ \\
\hline Median(GR) & $0.0064(0.0019)$ & $0.0063(0.0017)$ \\
\hline Standard $\operatorname{dev}(\mathrm{GR})$ & $0.0778(0.0098)$ & $0.0783(0.0095)$ \\
\hline $\operatorname{Mad}(G R)$ & $0.0478(0.0046)$ & $0.0480(0.0050)$ \\
\hline Skewness(GR) & $-0.4540(0.0936)$ & $-0.4522(0.0864)$ \\
\hline Robust skewness(GR) & $-0.0879(0.0256)$ & $-0.0860(0.0243)$ \\
\hline Kurtosis(GR) & $3.7056(0.3928)$ & $3.7451(0.3602)$ \\
\hline Robust kurtosis(GR) & $1.3063(0.0757)$ & $1.3056(0.0721)$ \\
\hline Median(BD) & $19.6307(2.7042)$ & $19.1947(1.8256)$ \\
\hline $\operatorname{Mad}(B D)$ & $11.0082(2.8201)$ & $10.3755(1.8527)$ \\
\hline Robust skewness(BD) & $0.9113(0.0746)$ & $0.9060(0.0727)$ \\
\hline Robust kurtosis(BD) & $6.5039(8.6971)$ & $5.9367(8.1410)$ \\
\hline Robust skewness(FSD) & $0.8245(0.0697)$ & $0.8106(0.0775)$ \\
\hline Robust kurtosis(FSD) & $1.2215(0.1145)$ & $1.4211(0.1386)$ \\
\hline Robust skewness(NDD) & $0.5986(0.0556)$ & $0.3087(0.1462)$ \\
\hline Robust kurtosis(NDD) & $1.5908(0.2357)$ & $1.3944(0.1395)$ \\
\hline Defaults: $\operatorname{corr}(\mathrm{D}, \mathrm{U})$ & $0.3555(0.0283)$ & $0.3472(0.0262)$ \\
\hline Defaults: $\operatorname{corr}(\mathrm{D}, \mathrm{B})$ & $0.0821(0.0363)$ & $0.0632(0.0315)$ \\
\hline Defaults: $\operatorname{corr}(\mathrm{U}, \mathrm{B})$ & $0.3616(0.0610)$ & $0.3562(0.0344)$ \\
\hline Default probability & $0.0458(0.0000)$ & $0.0452(0.0000)$ \\
\hline Default prob.: D & $0.0664(0.0000)$ & $0.0665(0.0000)$ \\
\hline Default prob.: U & $0.0195(0.0000)$ & $0.0183(0.0000)$ \\
\hline Default prob.: B & $0.0081(0.0019)$ & $0.0061(0.0000)$ \\
\hline
\end{tabular}

From Table 3 we infer that the correlation between bankruptcies in different sectors is positive as expected but not uniform across sectors. The coefficient of correlation between $\mathrm{D}$ and $\mathrm{U}$ defaults is 0.35 in both scenarios, while the correlation between D and B defaults is a modest 0.06 (in RM) or 0.08 (in EPC): the bankruptcy of downstream firms is highly correlated with the default of upstream firms but not significantly correlated with the bankruptcy of banks. On the contrary, the latter is highly correlated with the bankruptcy of upstream firms: the coefficient of correlation between D and $U$ defaults is 0.36 in both cases. The defaults of one or more $D$ firms yield a deterioration of the financial conditions of $U$ firms, spreads bankruptcies among $U$ firms and propagates through this channel to the banking sector.

The total default probability (e.g. the probability that an agent fails in a given period) is equal to $4.5 \%$ both in EPC and in $\mathrm{RM}$. The bankruptcy probability of D firms is also similar in the two setting (6.6\%). The bankruptcy probability of U firms is almost $2 \%$ in EPC and about $1.8 \%$ in RM. Furthermore, the bankruptcy probability of banks is $0.8 \%$ in EPC and $0.6 \%$ in RM: the endogenous formation of the network produces a configuration of productive and credit interlinkages that slightly increases the average probability of bankruptcy among upstream firms and banks.

\subsection{Sensitivity analysis}

Let us now investigate the sensitivity of simulation results to the change of parameter values. We focus on six parameters: $\phi, \beta, u_{\min }, \alpha, \lambda$, and $M .{ }^{16}$ We run 10 simulations for each value of each parameter varying in a certain range, leaving the other parameters unchanged, to analyze changes in macro-properties, the incidence of bad debt, defaults correlation and bankruptcy probabilities.

The results are summarized in Figs. 7-12. For increasing values of the parameter under consideration, the six panels of the figures display the following outputs: (1) the standard deviation of aggregate growth rates, that is std(GR); (2) the skewness of aggregate growth rates, skew(GR); (3) the kurtosis of aggregate growth rates, $k u r t(G R) ;(4)$ the median of aggregate bad debt, median(BD); (5) the default correlation between $\mathrm{D}$ and $\mathrm{U}$ firms, i.e. corr(D,U), and between $\mathrm{U}$ firms and banks, that is $\operatorname{corr}(\mathrm{U}, \mathrm{B}) ;(6)$ the overall bankruptcy probability, $P B$, and the bankruptcy probability of banks, $P B B$.

Varying the parameter $\phi$ : Let us consider discrete changes of the parameter $\phi$ from 1.2 to 3 . Fig. 7 shows that this when this parameter goes up, the dispersion of growth rates increases while skewness becomes negative and bigger in absolute value. The median value of aggregate bad debt increases markedly for values of $\phi$ above 2, producing a remarkable increase of the probability of banks' defaults PBB (see the last panel) due to the large incidence of non-performing loans on banks'

\footnotetext{
${ }^{16}$ We leave the other parameters unchanged since the parameters of the firms' input requirement functions, $\delta_{d}, \delta_{u}$, and $\gamma$, are related to technological issues we do not analyze in this paper. For similar reasons, the wage is a parameter which does not change across agents and over time, due to the lack of realistic assumptions about the functioning of the labour market.
} 

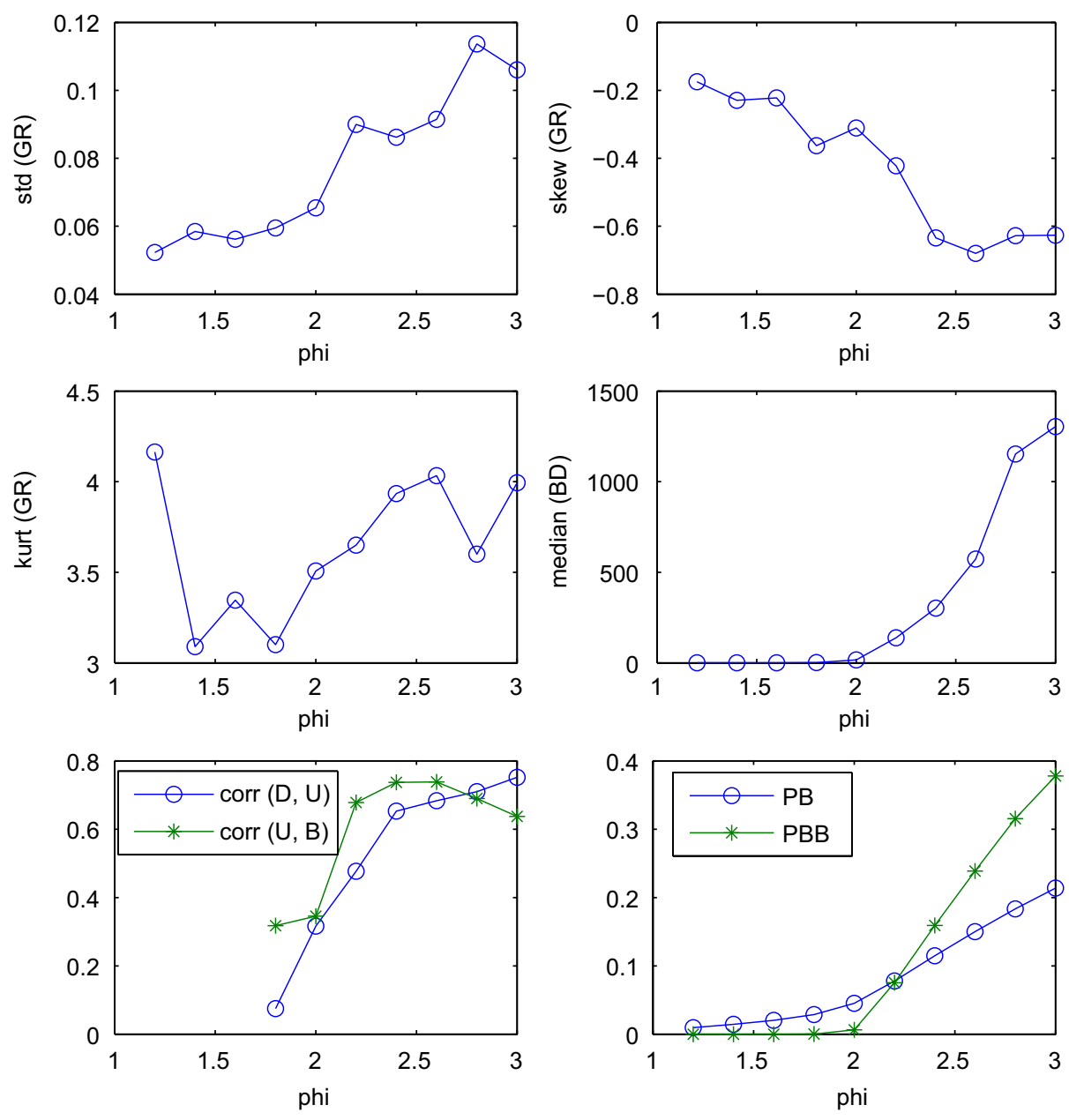

Fig. 7. Sensitivity analysis, the parameter $\phi$.

balance sheets. ${ }^{17}$ The correlation of defaults between any pair of sectors increases with $\phi$. The explanation of these results may be the fact that the leverage of both $\mathrm{D}$ and $\mathrm{U}$ firms is increasing with $\phi$ (see Eqs. (7) and (9) above) so that an increase of the latter leads to higher financial fragility and systemic risk.

Varying the parameter $\beta$ : Fig. 8 shows the effects of discrete changes of the parameter $\beta$ from 0.5 to 0.95 . Higher values of $\beta$ produce an increase of output volatility. Skewness and kurtosis of the GR distribution are non-monotonic functions of $\beta$ : skewness increases up to $\beta=0.6$ and then decreases and becomes negative while kurtosis decreases up to $\beta=0.8$ and then increases.

Median bad debt increases up to $\beta=0.6$ and then decreases. Also the aggregate probability of bankruptcy PB increases slightly up to $\beta=0.8$ and then decreases. The probability of bankruptcy of banks is unequivocally decreasing with $\beta$. Notice that according to Eqs. (7) and (9) the leverage of both D and U firms is increasing with $\beta$ (keeping net worth constant).

Both $\phi$ and $\beta$ affect the output-net worth relationship for D firms. The effects of changes in $\beta$, however, are quite different from those produced by varying $\phi$. Although an increase of either parameter generates more volatility at the aggregate level, the increase of $\phi$ produces more bad debt and, consequently, an increase of defaults, due to the higher incidence of non-performing loans on lenders' balance sheets. Instead, an increase of $\beta$ has non-monotonic effects on the relevant statistics.

Varying the parameter $\alpha$ : The effects of varying the value of parameter $\alpha$ in the interval (0.005-0.025) are summarized in Fig. 9. Higher values of this parameter reduce output volatility and increase kurtosis, while skewness oscillates but remains negative. The median bad debt and the probability of banks' failures PBB are clearly decreasing with $\alpha$. This effect can be traced back to the fact that a higher $\alpha$, increasing the level of interest rates charged on bank loans, ceteris paribus, produces higher profits. The financial condition of banks is also strengthened by the reduction of non-performing loans. On the other hand the average default rate shows a slight increase.

\footnotetext{
${ }^{17}$ The same pattern can be detected for the probability of default of $U$ firms, not reported in the figure.
} 

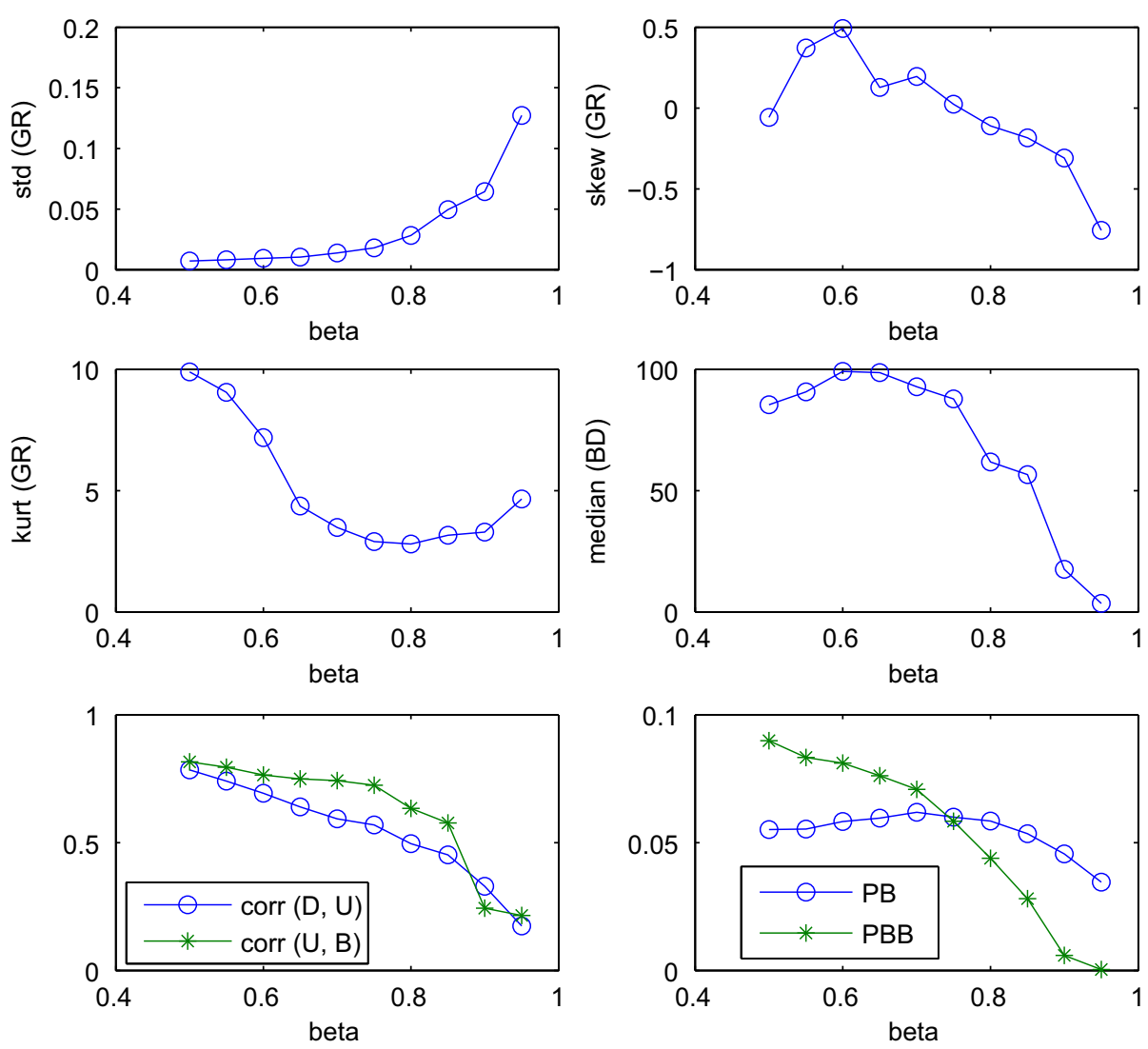

Fig. 8. Sensitivity analysis, the parameter $\beta$.

Varying the parameter $u_{\min }$ : Let us now analyze the effects of changes in the degree of uncertainty faced by D firms. We consider discrete changes of the parameter $u_{\min }$ from 0 to 1 . An increase of $u_{\min }$ yields a reduction of price volatility and therefore uncertainty for D firms. Not surprisingly, the reduction of price volatility at the firm-level-i.e. the increase of $u_{\min }$-yields a reduction of output volatility at the aggregate level, as shown in Fig. 10. There is a clear pattern also in the relationship between $u_{\min }$ and the skewness of GR: the latter is negative for low levels of $u_{\min }$ and increases with $u_{\min }$ turning positive for values of $u_{\min }$ larger than 0.5 . Median debt and the probabilities of bankruptcy are also decreasing with $u_{\min }$ : for high enough levels of $u_{\min }$ (greater than 0.5 ) there are no bad debts and no lenders' defaults.

Varying the parameter $\lambda$ : We explore the effects of changing the parameter $\lambda$ for a very large region of the parameter support. ${ }^{18}$ The main effects of an increase of $\lambda$ are an increase of the median bad debt, of the correlation between $U$ firms' and banks' defaults, and an increase of the bankruptcy probability of banks. Fig. 11 shows that these effects are significant for quite "high" values of the parameter under consideration. ${ }^{19}$

Varying the parameter $M$ : The effects of changing the fraction of potential partners $M$ are summarized in Fig. 12. The increase of $M$ is responsible for a slight increment of output volatility, bad debt and defaults' correlation. In general, higher values of $M$ increase volatility because of a higher probability of changing the partner according to the endogenous matching process.

\subsection{Shocks on the parameters}

After having evaluated the effects on the properties of the model of changing one parameter at a time by discrete steps, in this section we perform an experiment consisting of 300 simulations in which the values of the parameters are drawn from a normal distribution with mean equal to the values of the parameters in the baseline model (see Table 2 above) and $5 \%$ standard deviation. We focus $\phi, \beta$ and $u_{\min }$ because these parameters have a major impact on the properties of the model as shown in the previous subsection. ${ }^{20}$

\footnotetext{
18 We consider the parameters' values from $\lambda=0.0001$ to 100000 , according to a $\log 10$ scale.

${ }^{19}$ For instance, a remarkable increase of bad debt or banks' default probability is observable for $\lambda>100$.

${ }^{20}$ In the case of the parameter $\beta$ we fix at 0.99 the maximum value it can assume.
} 

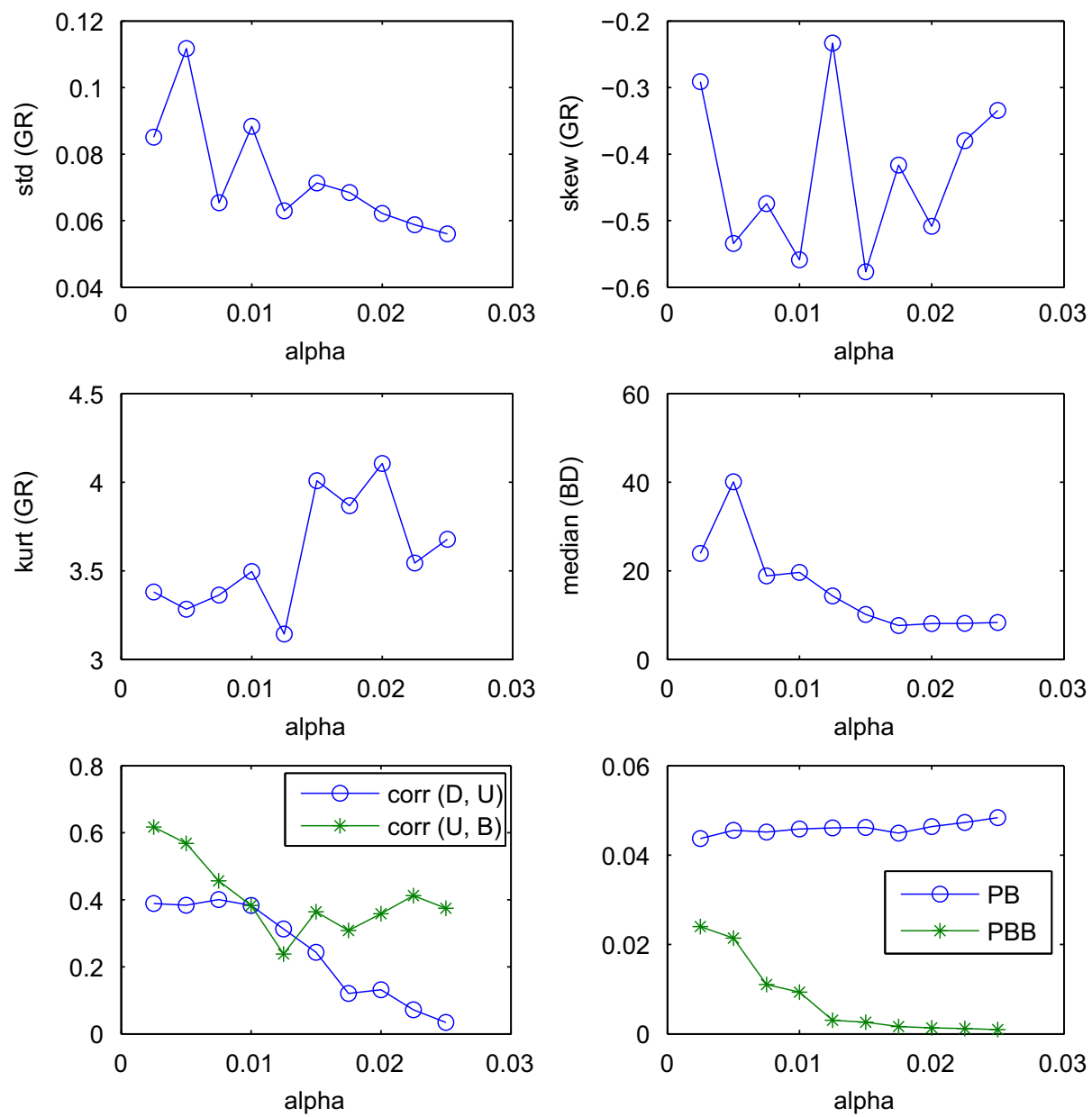

Fig. 9. Sensitivity analysis, the parameter $\alpha$.

In Tables 4-6 we report the average across simulations of robust statistics on aggregate growth rates, bad debt, default correlations and bankruptcy probabilities. In each table the statistics refer to simulations in which the parameter's value is "high" (for example, $\phi>2$ ) or "low" (for example, $\phi \leq 2$ ); the last column (labelled all) reports the averages across all simulations, which we use as a benchmark to evaluate the effects of parameters' changes on model behaviour.

Shocks on the parameters: the role of $\phi$ : According to the results of Section 8.2, the increase of the parameter $\phi$ produces an increase of systemic risk due to the increasing leverage of borrowers. An increase of $\phi$ also produces a moderate increase of the median growth rate, meaning that the economy may grow rapidly with favourable credit conditions and rising level of leverage, at the cost of increasing financial instability and systemic risk.

Shocks on the parameters: the role of $\beta$ : An increase of the value of $\beta$ brings about higher volatility, as measured by the median absolute deviation, higher kurtosis and (negative) skewness. This increase in volatility is associated with a moderate increase of the median growth rate. Then, the parameter $\beta$ has an influence similar to that of $\phi$ on aggregate growth rates.

Instead, the effects on bad debt of increasing $\beta$ are quite different from those caused by increasing $\phi$. Values of $\beta$ larger than 0.9 are associated with a lower value of the median, median absolute deviation, skewness (in absolute term), and kurtosis of bad debt than in the average case where all parameters are changing. This effect on bad debt also explains the results on default correlation and bankruptcy probabilities: when the incidence of non-performing loans on lenders' balance sheets is modest, the bankruptcy rate falls and the default correlation across sectors decreases. ${ }^{21}$

\footnotetext{
21 Let us consider Eq. (1), that is the financially constrained production function: given a certain value of $\phi$ and $\beta$, D firms' production will increase lesser than proportionally to the net worth $A$. For "low" levels of $\beta$, only "small" firms (in terms of net worth) need credit to finance production, while the fraction of indebted firms rises for increasing values of $\beta$. For example, if $\phi=2$ and $\beta=0.75$, a D firm with a net worth equal to 100 would produce little more than 63; instead, if $\beta=0.95$ it would produce almost 159 , requiring additional finance. Furthermore, when the value of $\beta$ is "very small" the "low" level of activity does not allow them to accumulate net worth and improve financial soundness. This aspect is particularly relevant for those agents that needs credit to produce, that is "small" firms. All in all, a "small" value of $\beta$ is harmful for our credit network economy because of "very low" growth rates and "high" financial fragility due to the lack of net worth accumulation.
} 

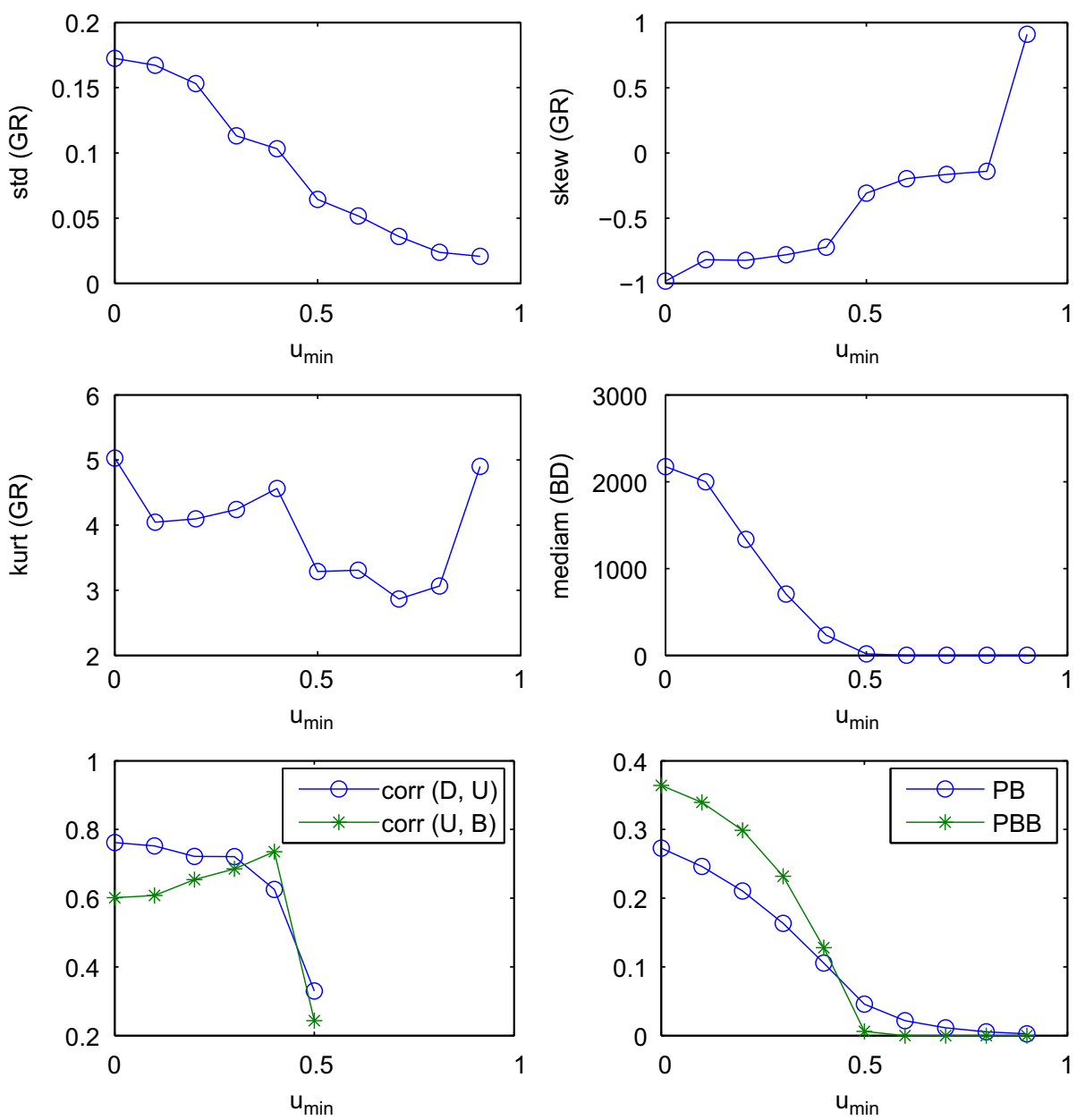

Fig. 10. Sensitivity analysis, the parameter $u_{m i n}$.

Shocks on the parameters: the role of $u_{\min }$ : The effect of $u_{\min }$ on aggregate growth rates is similar to that of $\phi$ and $\beta$ : "high" levels of price volatility for D firms, that is "low" values of the parameter $u_{\min }$, are associated with high levels of volatility, (negative) skewness, and kurtosis. In addition, the increase of volatility (that is, the decrease of $u_{\min }$ ) is also associated to a slight increase of the median of growth rates. Even in this case, the economy can grow more at the cost of higher systemic risk and instability. In general, the effects of diminishing $u_{\min }$ are similar to those generated by increasing $\phi$. It is worth noticing that for "high" levels of $u_{\min }$ there is a remarkable decrease of failures, due to the modest incidence of idiosyncratic shocks on D firms which lower the likelihood of bankruptcy chains.

Shocks on the parameters: joint effects: Let us now analyze the effects of various configurations of parameters' values. The results of this investigation are summarized in Tables 7 and 8 . The first one reports relevant statistics related to simulations in which the value of $\phi$ is smaller or equal to 2, while Table 8 reports results when $\phi$ is larger than 2 . In both tables the values of the other two parameters can be either "high" or "low". All in all, we have $2^{3}$ combinations of parameters' values, considering that we compare the averages across simulations for various combinations of "high" or "low" levels of $\phi, \beta$, and $u_{\min }$.

If we order the various scenarios according to the median of growth rates we observe the lowest values when $\beta \leq 0.9$ and $u_{\min }>0.5$, independently of the value of $\phi$ (which has a moderate influence also on other statistics for this range of values of $\beta$ and $u_{\min }$ ). The median of growth rates is quite "low" also with $u_{\min } \leq 0.5$ when $\beta \leq 0.9$. Hence $\beta$ has an important role in influencing the level of the median of growth rates. As said above, higher values of $\beta$ lead to more production and net worth accumulation which in turn result in higher growth associated with rate of bankruptcies which is "not-too-high".

There is an important interaction between $\beta$ and $u_{\min }$ : "high" levels of $\beta$ do not cause large bankruptcy chains especially when the volatility of the stochastic prices is "low". It is worth noting that an increase of price volatility mitigates the "positive" effects of $\beta$ described above, causing a rise of bad debt and defaults, but also an increase of the median of growth rates. 

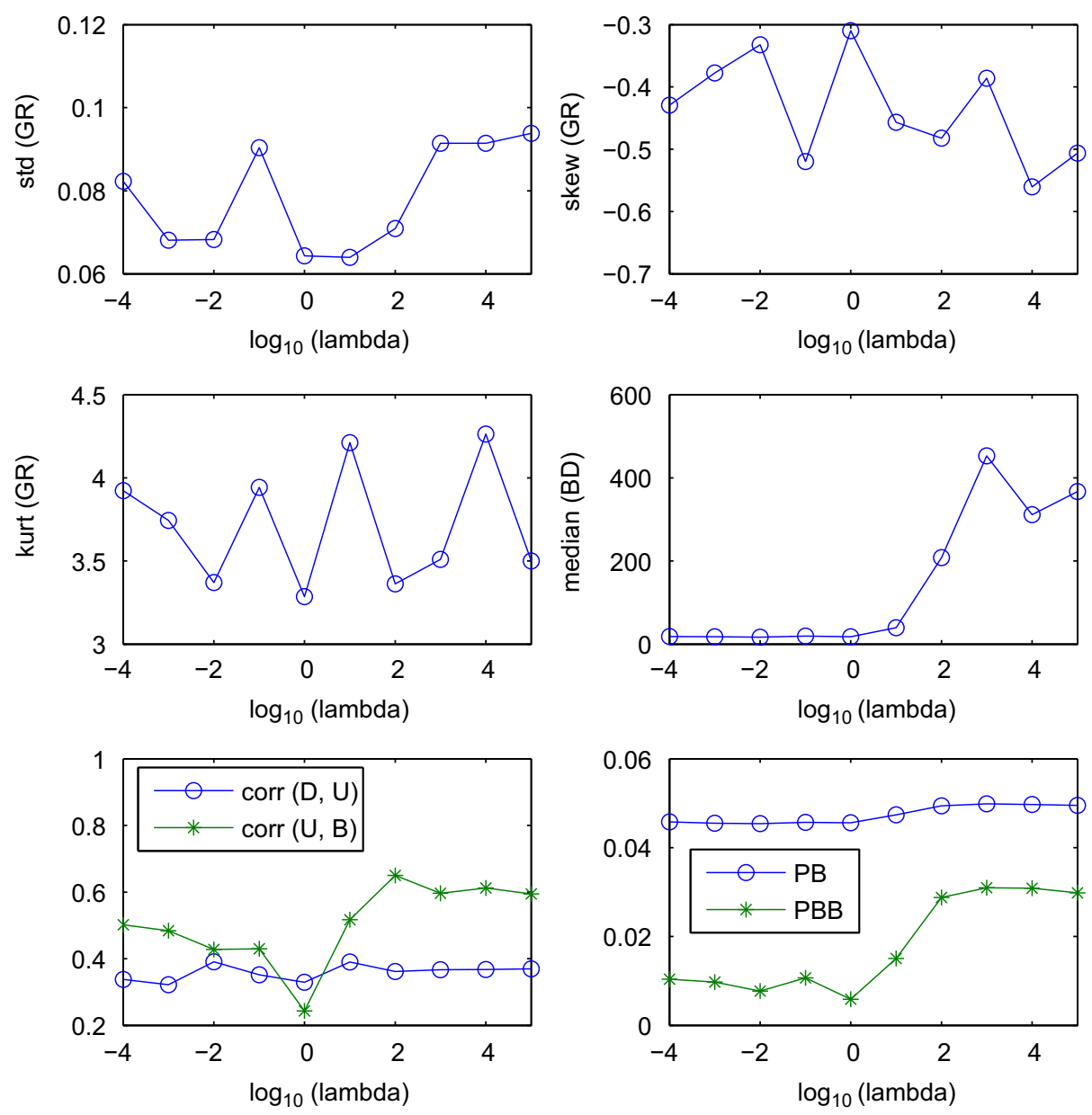

Fig. 11. Sensitivity analysis, the parameter $\lambda$.

To sum up, an increase of $\phi$ or a decrease of $u_{\min }$ produces a higher median of growth rates but also more volatility, more bad debt, and an increase of bankruptcy rates and default correlation. Higher values of $\beta$ generate higher growth rates, without causing large bankruptcy chains for modest values of $\phi$ and of price volatility. For a given, "high" value of $\beta$, an increase of $\phi$ and a decrease of $u_{\min }$ further improve economic performance at the cost of increasing financial instability and systemic risk.

\section{Concluding remarks}

We have explored the emergence of a network-based financial accelerator in a credit network characterized by inside credit (i.e. credit relationships connecting agents belonging to different groups of the same sector, i.e. D firms and U firms) and outside credit (i.e. credit relationships connecting agents belonging to different sectors, i.e. firms and banks). D firms are pure borrowers: they borrow from U firms (trade credit) and from banks (bank loans). Banks are pure lenders: they lend to $\mathrm{D}$ and $\mathrm{U}$ firms. $\mathrm{U}$ firms are borrowers and lenders at the same time: they borrow from banks and lend to $\mathrm{D}$ firms.

Since D output is constrained only by the availability of funds, in the end, the supply of consumption goods is increasing with $\mathrm{D}$ net worth. The net worth of $\mathrm{D}$ firms turns out to be the driver of growth and fluctuations. $U$ production, in fact, is determined by demand of intermediate inputs on the part of $\mathrm{D}$ firms. Changes in the $\mathrm{D}$ net worth, therefore, yield changes in the same direction of $U$ production.

The bankruptcy of a borrower-e.g. a D firm-affects the lender's balance sheet, which will record a non-performing loan. The response of the lender to bad debt will be an increase of the interest rate charged to all the other borrowers.

Some of the borrowers will switch to lenders who extend credit at more favourable conditions - the partner's selection mechanism is in fact based on the comparison of the interest rates charged by the original lender and by her competitors-some others will stick to the original lender.

Most likely, the surviving borrowers (who have not changed partner) will experience an increase of leverage due to the interest rate hike. The borrower's net worth, in fact, is a proxy of creditworthiness. Hence the "price" of credit-i.e. the 

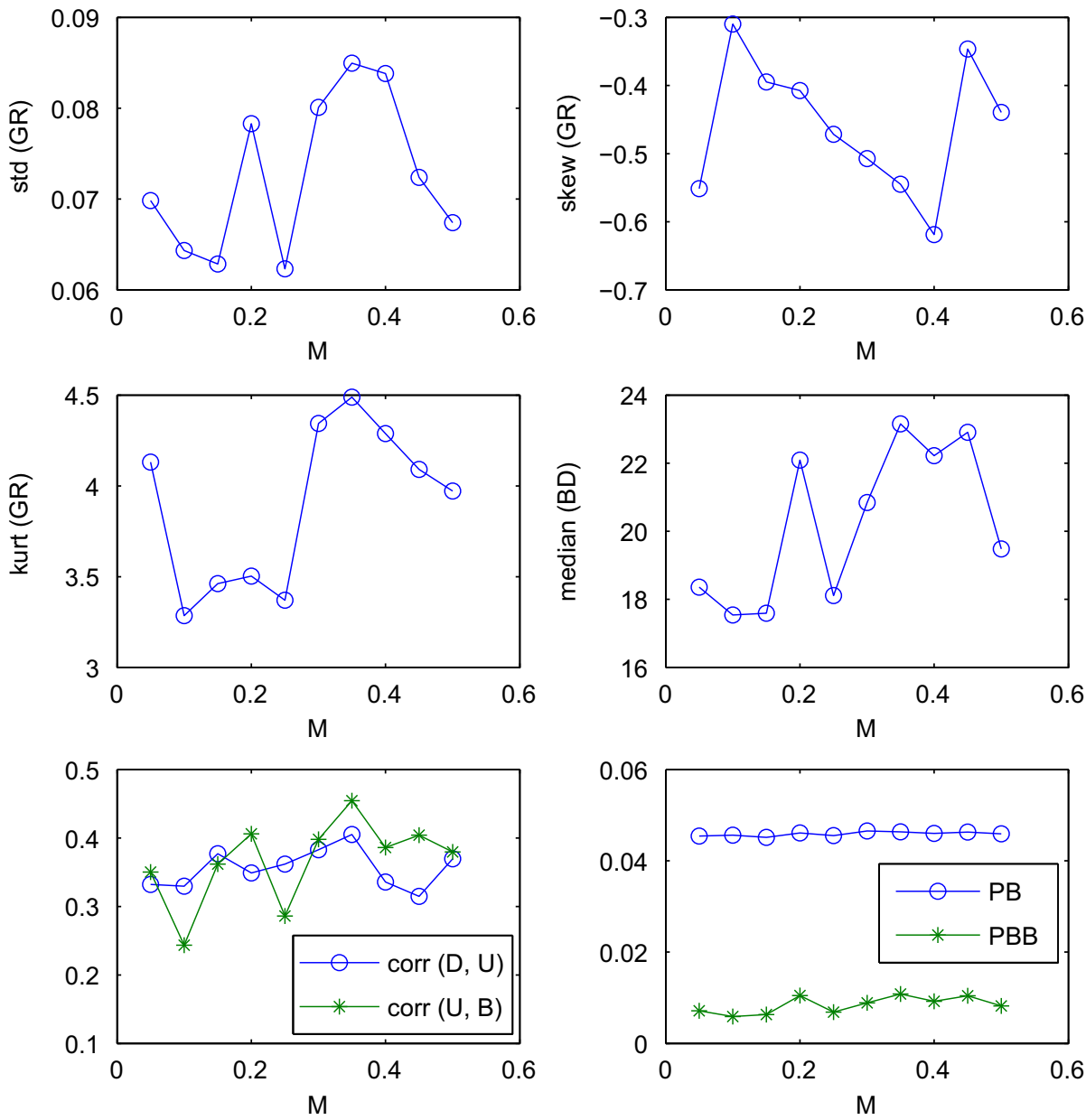

Fig. 12. Sensitivity analysis, the parameter $M$.

Table 4

Shocks on the parameters: the role of $\phi$.

\begin{tabular}{lrrr}
\hline & $\phi \leq 2$ & $\phi>2$ & All \\
\hline Median(GR) & 0.0067 & 0.0083 & 0.0075 \\
Mad(GR) & 0.0467 & 0.0507 & 0.0486 \\
Rob. skewness(GR) & -0.0822 & -0.0939 & 1.0880 \\
Rob. kurtosis(GR) & 1.2962 & 1.3010 & 74.4483 \\
Median(BD) & 45.5683 & 103.7159 & 46.3049 \\
Mad(BD) & 26.5716 & 66.3031 & 0.7191 \\
Rob. skewness(BD) & 0.6906 & 0.7479 & 2.5403 \\
Rob. kurtosis(BD) & 2.2763 & 2.8078 & 0.3547 \\
Defaults: corr(D,U) & 0.3180 & 0.3896 & 0.1840 \\
Defaults: corr(D,B) & 0.1573 & 0.2089 & 0.4905 \\
Defaults: corr(U,B) & 0.4635 & 0.5155 & 0.0491 \\
Default prob.. & 0.0441 & 0.0542 & 0.0645 \\
Default prob.: D & 0.0602 & 0.0688 & 0.0265 \\
Default prob.: U & 0.0210 & 0.0320 & 0.0362 \\
Default prob.: B & 0.0212 & 0.0287 \\
\hline
\end{tabular}

interest rate-is decreasing with the borrowers' net worth. The higher the leverage of the borrower, the higher the interest rate charged by the lender.

The lender will react to the increase of the borrowers' leverage by raising the interest rate even further. Financial fragility will spread to the neighbourhood and possibly to the economy overall. Some borrowers already on the verge of 
Table 5

Shocks on the parameters: the role of $\beta$.

\begin{tabular}{lrrr}
\hline & $\beta \leq 0.9$ & $\beta>0.9$ & All \\
\hline Median(GR) & 0.0041 & 0.0115 & 0.0075 \\
Mad(GR) & 0.0347 & 0.0652 & 0.0486 \\
Rob. skewness(GR) & -0.0644 & -0.1161 & 1.0880 \\
Rob. kurtosis(GR) & 1.2576 & 1.3473 & 74.4483 \\
Median(BD) & 109.9091 & 32.2576 & 46.3049 \\
Mad(BD) & 71.7013 & 16.0888 & 0.7191 \\
Rob. skewness(BD) & 0.7262 & 0.7106 & 2.5403 \\
Rob. kurtosis(BD) & 2.4702 & 2.6237 & 0.3547 \\
Defaults: corr(D,U) & 0.4023 & 0.2861 & 0.1840 \\
Defaults: corr(D,B) & 0.2241 & 0.1239 & 0.4905 \\
Defaults: corr(U,B) & 0.4795 & 0.5070 & 0.049 \\
Default prob. & 0.0559 & 0.0409 & 0.0566 \\
Default prob.: D & 0.0710 & 0.0185 & 0.0265 \\
Default prob.: U & 0.0333 & 0.0186 & 0.0287 \\
Default prob.: B & 0.0371 & & \\
\hline
\end{tabular}

Table 6

Shocks on the parameters: the role of $u_{\text {min }}$.

\begin{tabular}{|c|c|c|c|}
\hline & $u_{\min }>0.5$ & $u_{\min } \leq 0.5$ & All \\
\hline Median(GR) & 0.0062 & 0.0090 & 0.0075 \\
\hline $\operatorname{Mad}(G R)$ & 0.0447 & 0.0530 & 0.0486 \\
\hline Rob. skewness(GR) & -0.0777 & -0.0995 & -0.0880 \\
\hline Rob. kurtosis(GR) & 1.2915 & 1.3064 & 1.2986 \\
\hline Median(BD) & 11.3436 & 144.6633 & 74.4483 \\
\hline $\operatorname{Mad}(\mathrm{BD})$ & 5.7778 & 91.3985 & 46.3049 \\
\hline Rob. skewness(BD) & 0.6260 & 0.8226 & 0.7191 \\
\hline Rob. kurtosis(BD) & 1.9598 & 3.1862 & 2.5403 \\
\hline Defaults: $\operatorname{corr}(\mathrm{D}, \mathrm{U})$ & 0.2223 & 0.4750 & 0.3547 \\
\hline Defaults: $\operatorname{corr}(\mathrm{D}, \mathrm{B})$ & 0.0872 & 0.2646 & 0.1840 \\
\hline Defaults: $\operatorname{corr}(\mathrm{U}, \mathrm{B})$ & 0.3569 & 0.6015 & 0.4905 \\
\hline Default prob. & 0.0328 & 0.0672 & 0.0491 \\
\hline Default prob.: D & 0.0503 & 0.0802 & 0.0645 \\
\hline Default prob.: U & 0.0086 & 0.0464 & 0.0265 \\
\hline Default prob.: B & 0.0056 & 0.0543 & 0.0287 \\
\hline
\end{tabular}

Table 7

Shocks on the parameters, joint effects: $\phi \leq 2$.

\begin{tabular}{|c|c|c|c|c|}
\hline & $\begin{array}{l}\beta \leq 0.9 \\
u_{\min }>0.5\end{array}$ & $\begin{array}{l}\beta \leq 0.9 \\
u_{\min } \leq 0.5\end{array}$ & $\begin{array}{l}\beta>0.9 \\
u_{\min }>0.5\end{array}$ & $\begin{array}{l}\beta>0.9 \\
u_{\min } \leq 0.5\end{array}$ \\
\hline Median(GR) & 0.0031 & 0.0048 & 0.0090 & 0.0119 \\
\hline $\operatorname{Mad}(G R)$ & 0.0305 & 0.0368 & 0.0603 & 0.0679 \\
\hline Rob. skew.(GR) & -0.0525 & -0.0728 & -0.1039 & -0.1130 \\
\hline Rob. kurt.(GR) & 1.2383 & 1.2728 & 1.3508 & 1.3474 \\
\hline Median(BD) & 12.1965 & 114.0951 & 0.7572 & 56.4915 \\
\hline $\operatorname{Mad}(B D)$ & 5.7766 & 70.0601 & 0.2359 & 30.2394 \\
\hline Rob. skew.(BD) & 0.6494 & 0.7860 & 0.4882 & 0.8767 \\
\hline Rob. kurt.(BD) & 1.8889 & 2.8949 & 1.3222 & 3.2070 \\
\hline Defaults: $\operatorname{corr}(\mathrm{D}, \mathrm{U})$ & 0.2485 & 0.4868 & 0.0463 & 0.3675 \\
\hline Defaults: $\operatorname{corr}(\mathrm{D}, \mathrm{B})$ & 0.1027 & 0.2829 & 0.0096 & 0.1345 \\
\hline Defaults: corr(U,B) & 0.2631 & 0.6110 & 0.5270 & 0.4895 \\
\hline Default prob. & 0.0365 & 0.0655 & 0.0215 & 0.0539 \\
\hline Default prob.: D & 0.0558 & 0.0790 & 0.0364 & 0.0704 \\
\hline Default prob.: U & 0.0103 & 0.0445 & 0.0004 & 0.0304 \\
\hline Default prob.: B & 0.0057 & 0.0507 & 0.0001 & 0.0298 \\
\hline
\end{tabular}


Table 8

Shocks on the parameters, joint effects: $\phi>2$.

\begin{tabular}{|c|c|c|c|c|}
\hline & $\begin{array}{l}\beta \leq 0.9 \\
u_{\min }>0.5\end{array}$ & $\begin{array}{l}\beta \leq 0.9 \\
u_{\min } \leq 0.5\end{array}$ & $\begin{array}{l}\beta>0.9 \\
u_{\min }>0.5\end{array}$ & $\begin{array}{l}\beta>0.9 \\
u_{\min } \leq 0.5\end{array}$ \\
\hline Median(GR) & 0.0031 & 0.0059 & 0.0105 & 0.0148 \\
\hline $\operatorname{Mad}(G R)$ & 0.0307 & 0.0420 & 0.0622 & 0.0713 \\
\hline Rob. skew.(GR) & -0.0504 & -0.0848 & -0.1127 & -0.1351 \\
\hline Rob. kurt.(GR) & 1.2554 & 1.2661 & 1.2661 & 1.3545 \\
\hline Median(BD) & 25.6849 & 314.7990 & 4.8486 & 73.6708 \\
\hline $\operatorname{Mad}(B D)$ & 13.8436 & 216.0295 & 2.2890 & 35.3167 \\
\hline Rob. skew.(BD) & 0.7141 & 0.7648 & 0.6390 & 0.8817 \\
\hline Rob. kurt.(BD) & 2.5871 & 2.5610 & 1.9871 & 4.1711 \\
\hline Defaults: $\operatorname{corr}(\mathrm{D}, \mathrm{U})$ & 0.3339 & 0.5573 & 0.1464 & 0.4635 \\
\hline Defaults: $\operatorname{corr}(\mathrm{D}, \mathrm{B})$ & 0.1521 & 0.3630 & 0.0080 & 0.2468 \\
\hline Defaults: $\operatorname{corr}(\mathrm{U}, \mathrm{B})$ & 0.3688 & 0.6785 & 0.3763 & 0.6019 \\
\hline Default prob. & 0.0427 & 0.0830 & 0.0283 & 0.0637 \\
\hline Default prob.: D & 0.0610 & 0.0914 & 0.0457 & 0.0779 \\
\hline Default prob.: U & 0.0179 & 0.0650 & 0.0042 & 0.0423 \\
\hline Default prob.: B & 0.0135 & 0.0855 & 0.0021 & 0.0458 \\
\hline
\end{tabular}

bankruptcy may reach a tipping point and default. An avalanche of bankruptcies may ensue. This is, in a nutshell, the way in which the network-based financial accelerator amplifies a shock.

The output of simulations shows that a business cycle at the macroeconomic level can develop as a consequence of the complex interactions of the financial conditions of the agents involved. The network structure changes over time due to an endogenous mechanism of partner selection, which implies that changes of the interest rate on trade credit and on bank loans affect the number of clients of each $U$ firm and each bank. The endogeneous mechanism of partner selection affects essentially the skewness and the kurtosis of the credit network's degree distribution, increasing the likelihood of bankruptcy chains involving large firms or banks.

From the exploration of the parameter space we can infer that the credit network economy we have modelled can exhibit higher growth rates by extending more credit to finance increasing levels of production. The consequent rise of agents' leverage, the extent of which depends on the parameters' configuration, may cause an increase of systemic risk, that is a higher likelihood of bankruptcy episodes potentially leading to the deterioration of the system's financial conditions.

This is a step in a complex and difficult quest for a "complete" credit network. There are obvious restrictions on the conditions determining the model environment which we plan to relax in the future. For instance, we would like to extend the partner choice rule also to the market for consumption goods and to the labour market. This will imply a more sophisticated design of households' behaviour, which so far has been essentially passive. Another obvious extension is the introduction of an interbank market, which will allow modelling the central bank and monetary policy.

\section{Acknowledgements}

We are grateful for insightful comments and criticisms to participants to the Eastern Economic Association meeting, New York City, February 2007, and in particular to Duncan Foley, the Net-Work-shop at Catholic University in Milan, April 2007, the Annual Meeting of the Italian Economists' Society in Turin, October 2007, the International Conference on Economic Science with Heterogeneous Interacting Agents in Warsaw, June 2008, the 14th International Conference on Computing in Economics and Finance in Paris, June 2008, the CeNDEF anniversary conference at the University of Amsterdam, January 2009 and the International Conference on Public Economic Theory, July 2009. Financial support from the European Community's Seventh Program (FP7/2007-2013) under Socio-Economic Sciences and Humanities, grant agreement no. 225408, project "Monetary, Fiscal and Structural Policies with Heterogeneous Agents (POLHIA)" is gratefully acknowledged. We are indebted to two anonymous referees and to the editors of this special issue for very useful criticisms and suggestions. All remaining errors are the sole responsibility of the authors.

\section{References}

Adrian, T., Shin, H., 2008. Liquidity, monetary policy and financial cycles. Current Issues in Economics and Finance 14 (1), Federal Reserve Bank of New York (January/February).

Allen, F., Gale, D., 2001. Financial contagion. Journal of Political Economy 108, 1-33.

Allen, L., Saunders, A., 2004. Incorporating systemic influences into risk measurements: a survey of the literature. Journal of Financial Services Research 26 (2), 161-191.

Bak, P., Chen, K., Scheinkman, J., Woodford, M., 1993. Aggregate fluctuations from independent sectoral shocks: self-organized criticality in a model of production and inventory dynamics. Ricerche Economiche 47, 3-30. 
Barabàsi, A.-L., Albert, R., 1999. Emergence of scaling in random networks. Nature 286, 509-512.

Battiston, S., Delli Gatti, D., Gallegati, M., Greenwald, B., Stiglitz, J.E., 2007. Credit chains and bankruptcies avalanches in supply networks. Journal of Economic Dynamics and Control 31 (6), 2061-2084.

Bernanke, B., Gertler, M., 1989. Agency costs, net worth and business fluctuations. American Economic Review 79, $14-31$.

Bernanke, B., Gertler, M., 1990. Financial fragility and economic performance. Quarterly Journal of Economics 105, 87-114.

Bernanke, B., Gertler, M., Gilchrist, S., 1999. The financial accelerator in a quantitative business cycle framework. In: Taylor, J., Woodford, M. (Eds.), Handbook of Macroeconomics, vol. 1. North-Holland, Amsterdam, pp. 1341-1393.

Bianconi, G., Barabàsi, A.-L., 2001. Competition and multiscaling in evolving networks. Europhysics Letters 54 (4), $436-442$.

Boissay, F., 2006. Credit chains and the propagation of financial distress. Working Paper Series 573, January, European Central Bank.

Boss, M., Elsinger, H., Summer, M., Thurner, S., 2004. Network topology of the interbank market. Quantitative Finance 4 (6), 677-684.

Bruneau, C., de Bandt, O., El Amri, W., 2008. Macroeconomic fluctuations and corporate financial fragility. Notes d'études et de recherche 226, Banque de France.

Carling, K., Jacobson, T., Lindé, J., Roszbach, K., 2007. Corporate credit risk modelling and the macroeconomy. Journal of Banking and Finance 31 (3), $845-868$.

Delli Gatti, D., Gallegati, M., Greenwald, B., Russo, A., Stiglitz, J.E., 2006. Business fluctuations in a credit-network economy. Physica A 370, 68-74.

Delli Gatti, D., Gallegati, M., Greenwald, B., Russo, A., Stiglitz, J.E., 2009. Business fluctuations and bankruptcy avalanches in an evolving network economy. Journal of Economic Interaction and Coordination 4 (2), 195-212.

Fagiolo, G., Napoletano, M., Roventini, A., 2008. Are output growth-rate distributions fat-tailed? Some evidence from OECD countries. Journal of Applied Econometrics 23 (5), 639-669.

Freixas, X., Parigi, B.M., Rochet, J.C., 2000. Systemic risk, interbank relations and liquidity provision by the central bank. Journal of Money, Credit and Banking 32, 611-638.

Fujiwara, Y., 2008. Chain of firms' bankruptcy: a macroscopic study of link effect in a production network. Advances in Complex Systems 11 (5), 703-717.

Fujiwara, Y., Aoyama, H., Ikeda, Y., Iyetomi, H., Souma W., 2009. Structure and temporal change of the credit network between banks and large firms in Japan. Economics: The Open Access, Open Assessment E-Journal 3 (7).

Furfine, C.H., 2003. Interbank exposures: quantifying the risk of contagion. Journal of Money, Credit and Banking 35 (1), 111-128.

Gambacorta, L., 2008. How do banks set interest rates? European Economic Review 52, 792-819

Goyal, S., 2007. Connections. Princeton University Press, Princeton.

Greenwald, B., Stiglitz, J.E., 1993. Financial market imperfections and business cycles. Quarterly Journal of Economics $108,77-114$.

Groeneveld, R.A., Meeden, G., 1984. Measuring skewness and kurtosis. The Statistician 33, 391-399.

Iori, G., Jafarey, S., Padilla, F., 2006. Systemic risk on the interbank market. Journal of Economic Behaviour and Organization 61 (4), $525-540$.

Jackson, M.O., 2005. The economics of social networks. In: Blundell, R., Newey, W., Persson, T. (Eds.), Proceedings of the 9th World Congress of the Econometric Society. Cambridge University Press, Cambridge.

Jackson, M.O., 2008. Social and Economics Networks. Princeton University Press, Princeton.

Kashyap, A., Stein, J.C., 1995. The impact of monetary policy on bank balance sheets. In: Carnegie Rochester Conference Series on Public Policy, vol. 42, pp. 151-195.

Kashyap, A., Stein, J.C., 2000. What do a million observations on banks say about the transmission of monetary policy. American Economic Review 90 (3), 407-428.

Kishan, R.P., Opiela, T.P., 2000. Bank size, bank capital and the bank lending channel. Journal of Money, Credit and Banking 32 (1), $121-141$.

Lucas, D.J., McDonald, R.L., 1992. Bank financing and investment decisions with asymmetric information about loan quality. RAND Journal of Economics 23 (1), 86-105.

Lown, C., Morgan, D.P., 2006. The credit cycle and the business cycle: new findings using the loan officer opinion survey. Journal of Money, Credit and Banking 38 (6), 1575-1597.

Mateut, S., Bougheas, S., Mizen, P., 2006. Trade credit, bank lending and monetary policy transmission. European Economic Review 50, 603-629.

Minsky, H.P., 1982. Can "it" Happen Again? Essays on Instability and Finance. M.E. Sharpe, Armonk, NY.

Misina, M., Tessier, D., Dey, S., 2006. Stress testing the corporate loans portfolio of the Canadian banking sector. Working Paper 06-47, December, Bank of Canada.

Moors, J.J.E., 1988. A quantile alternative for kurtosis. The Statistician 37, 25-32.

Nadiri, M.I., 1969. The determinants of trade credit in the US total manufacturing sector. Econometrica 37 (3), $408-423$.

Nier, E., Yang, J., Yorulmazer, T., Alentorn, A., 2007. Network models and financial stability. Journal of Economic Dynamics and Control 31, 2033-2060.

Nilsen, J., 2002. Trade credit and the bank lending channel. Journal of Money, Credit and Banking 34, $227-253$.

Stein, J.C., 1998. An adverse-selection model of bank asset and liability management with implications for the transmission of monetary policy. RAND Journal of Economics 29 (3), 466-486.

Stiglitz, J.E., Greenwald, B., 2003. Towards a New Paradigm in Monetary Economics. Cambridge University Press, Cambridge.

Summers, B., Wilson, N., 2003. Trade credit and customer relationships. Managerial and Decision Economics 24, 439-455.

Vega-Redondo, F., 2007. Complex Social Networks. Econometric Society Monograph Series. Cambridge University Press, Cambridge. 